\title{
Spatial analysis of child mortality and welfare differentials in South Africa: evidences from the $201 \mathrm{I}$ census
}

\author{
Samuel Abera Zewdie ${ }^{1}$ \& Visseho Adjiwanou ${ }^{2}$ \\ ${ }^{1}$ Environment and Climate Research Centre, Ethiopian Development Research Institute, \\ Addis Ababa, Ethiopia. \\ ${ }^{2}$ Centre for Actuarial Research, University of Cape Town, \\ Cape Town, South Africa. \\ Email: samuel_abera@yahoo.com
}

\begin{abstract}
Background: Welfare differential is a common phenomenon among South African population which can be manifested in terms of various economic and health outcomes. Using child mortality (CM) as one of a key measure of the country's health system, the study attempted to show its spatial distribution and the association with economic disparities in the country.

Methods: The study primarily aimed to derive estimates of $C M$ rates for the municipalities and provinces of South Africa and assessed the results in relation to some welfare measures such as poverty and inequality. The estimation of CM rates was achieved through the use of direct synthetic cohort methods with Bayesian spatial smoothing. The smoothing process helped to generate accurate municipal level estimates of CM. The model utilized information from neighboring municipalities by controlling the effects of women's education and HIV.

Results: It was found that there were clear spatial differentials of CM in the country, where at province level under-five mortality (U5M) rate (deaths per 1000 live births) ranges from 26 in Western Cape to $7 \mathrm{I}$ in KwaZulu-Natal. At municipal level, it ranges from 24 in City of Cape Town to 109 in uPhongolo. It was also shown that CM was higher in poorer and more unequal areas, although there were cases which had inverse relationship. For instance, several municipalities in Limpopo province scored relatively lower child mortality rates though the level of poverty is very high

Conclusions: The study revealed significant spatial differentials of CM in the country, which were also associated with the level of poverty and income inequality. The findings may help local and national government to implement policies more effectively and make more focused decisions for a better health outcome.
\end{abstract}

Keywords: Spatial demography; family health; Bayesian smoothing; poverty; inequality.

\section{Introduction}

Disparities in health and mortality have been the concern of development agencies, governments and the international public health community for many years. Various declarations were signed by leaders of nations and representatives of key international organizations so that the gap would be reduced to a noteworthy level (WHO, 1978). Child mortality is considered to be one of the key measures of a country's health system, and rates of child mortality of an area have long been believed to be important indicators of health status and socioeconomic development (Kabir et al., 200I, IGME, 20I3). This is due to its sensitivity to various changes that affect the health of the entire population, such as disease epidemics and economic development, and to other changes that affect general living conditions, such as social well-being and the quality of the environment (Reidpath and Allotey, 2003).
According to a United Nations (UN) report, child mortality in South Africa has declined from 6I deaths per 1000 live births in 1990 to 45 deaths per 1000 live births in 2012 (IGME, 20I3). The performance, however, is low compared to many other countries' performance. For instance, the world has made substantial progress in reducing the under-five mortality (U5M) rate by $47 \%$ in the period 19902012 while South Africa has attained a reduction of only about $26 \%$. Although HIV/AIDS is usually quoted as the main reason for this poor performance, the role of poverty and inequality should not be ignored. It has been reported that the health of infants and children in South Africa is largely influenced by social and economic conditions under which they live and approximately $66 \%$ of children in the country live in poverty, with a monthly 
household income of less than RI200 per month (Whiting, 2013).

Accurate and timely estimates of child mortality at lower geographical units are very important for a country in order to evaluate the effectiveness of intervention programmes as well as for policy planning. Furthermore, child mortality rates in the country have been found to be much higher in certain geographical areas and certain disadvantaged social groups. Many studies in different countries show that the geographic distribution of health problems and their relationship to potential risk factors can be invaluable for cost-effective intervention planning (Freedman et al., 2005, McKinnon, 20l0). Addressing inequalities in health status and access to health care services within countries is as important as addressing these issues among countries, and hence, in order to effectively address the problem and work towards further reductions in child mortality in the country it is essential that the efforts be focused more on lower administrative levels as, at municipality level for example, opposed to concentrating only on the level of mortality at national level (Freedman et al., 2005).

In addition, studying this in relation to poverty and inequality will help to make more focused and potentially effective decisions. Many of the researches conducted so far on child mortality in South Africa lack comprehensiveness in that either they focus only on country or province level, or certain specific geographical areas. To the best of our knowledge, there is not any research which attempts to estimate child mortality of the country at municipal level. Besides, very few of these researches tried to analyse the relationship of child survival with poverty and inequality. Thus, this research is unique because it will provide new and comprehensive estimates of child mortality for the country at lower administrative units, specifically for the municipalities of South Africa, and it helps to see how these estimates are related with poverty and inequality.

The primary objective of this research is to estimate infant and child mortality rates for the municipalities and provinces of South Africa using the 2011 South African census and to study the spatial differentials in relation to poverty and inequality. The hypothesis is that there are significant spatial variations of child mortality, which is associated with socioeconomic differentials in the country, and hence deriving estimates at lower administrative levels helps to achieve faster and greater reduction of child mortality in the country.

Spatial differentials in child mortality in South Africa

Child mortality in South Africa is characterized by large spatial differentials which are strongly associated 4377 with the level of socio-economic disparities. Geographically, the country is divided into nine different provinces: Western Cape (WC), Eastern Cape (EC), Northern Cape (NC), Free State (FS), Gauteng (GT), North-West (NW), KwaZulu-Natal (KZN), Mpumalanga (MP) and Limpopo (LP); and 234 municipalities, each reflecting broad differences in geography, environment, population, and development. In the poorer provinces like LP and $M P$, there are relatively low levels of infrastructure development (housing, water, sanitation, electricity, etc.), education and income, higher unemployment rates, and poor health care services (UNICEF, 20I3, HSRC, 20I4b). In contrast, in richer provinces like WC and GT there are better infrastructure development, higher income and education levels. Child mortality rates in the poorer provinces are usually estimated to be very high compared to the richer provinces.

In reviewing the studies on spatial differential of child mortality in the country, differentials at province level are better studied by several researchers than differentials at municipal level or other lower geographical units. The work by Dorrington et al. (2004) reports provincial estimated trends of U5M rates from I 986 to 1996 using the 1996 census. Over the period considered, the lowest and highest mortalities were recorded in WC and EC respectively. The estimate for boys per 100 live births varied from 44 in WC to II4 in EC in 1986, while in 1996 it varied from 47 in WC to 102 in EC. Similarly, the estimates for girls, respectively for WC and EC, were 30 and 107 in 1986 and 32 and 87 in 1996. In their review of available empirical data on levels and causes of child mortality in South Africa in the period 1997-2007 Nannan et al. (2012) also show the trends of provincial estimates of infant mortality rates over the time period. It is indicated that in each of the provinces infant mortality was mostly increasing and, in some provinces, such as FS, NW, $M P$ and $G T$, the rate was much higher (above 50 deaths per 1000 live births).

One comprehensive source of national and provincial estimates of CM is the HIV and demographic model developed by the Actuarial Society of South Africa (ASSA). The 2008 version of the model shows that U5M rate in EC, FS, KZN and $\mathrm{MP}$ had been consistently higher as compared to the rates in the other provinces (ASSA, 2010). One can also note that CM was increasing in 2000 before it has started to decline in 2005 in all the provinces due to the HIV endemic as indicated previously for the national estimates.

Unlike the number of studies at national and provincial levels, the researches on measuring child mortality at lower geographical levels are very 
limited. One comparable attempt with this research is by Bangha and Simelane (2008), who have used the 200 I census data to map the spatial distribution of U5M mortality at magisterial district (MD) level. They have found a significant extent of differentials in CM among MDs. For instance, based on their computation, U5M rate per 1000 births among MDs ranges from 5.6 to as high as 108.5. However, it seems that they have somehow under-estimated the CM level in general. For example, it is very unlikely that provincial U5M rate in $200 \mathrm{I}$ ranges from as small as 19 deaths per 1000 births in WC to only 66 deaths per 1000 births in EC as they have reported. In another study, marked geographical differentials of infant mortality is observed among provinces, districts and sub-districts (Sartorius et al., 20ll). Especially, the Bayesian Poisson model containing only a constant and the conditional autoregressive parameters is fitted to estimate standardised mortality ratio (SMR) of infant deaths in the subdistricts of South Africa using the 2007 community survey data.

\section{Data and methods \\ Data source}

The study uses data from the $10 \%$ unit record of the $201 \mathrm{I}$ de facto population and housing census of South Africa. The main objective of the census was to provide statistics on population, demographic, social, economic and housing characteristics (StatsSA, 20I4a). Appropriate data quality assessments were carried out before using the data for our analysis.

\section{Methods of estimating child mortality}

Direct synthetic cohort method is the only feasible approach to estimate child mortality from the given census data. Reported deaths by households are used to compute infant and U5M rates. This is achieved by calculating a complete life table for children aged 0 to 4. First, infant mortality rate, an approximate estimate of $\mathrm{Iq0}$, is calculated by the ratio of the number of deaths of children under age land the number of births occurred I year before the census date.

The number of births occurred 12 months before the census are computed from the census question on day, month and year of the last birth administered to women of age 12-50 years at the census date. Then, the central mortality rate, ${ }_{1} M_{x}$ for children between ages $x$ and $x+1$ for $x=1,2,3,4$ are determined by dividing the number of deaths of children aged $x$ by their expected number of children or mid-year population. The mid-year population at age $\mathrm{x}$ are computed by first projecting back the number of survivors at the census date by exactly one year before the census using survival factors from ASSA 2008 demographic and AIDS model (ASSA, 2010) to get the population size one year before the census date and then taking the average of these projected numbers and the actual census counts. This implies that the number of children between age $x$ and $x+I$ about six months before the census, ${ }_{1} N_{x}$ is given by

$$
{ }_{1} N_{x}=\left(P_{x}^{t} \times P_{x}^{t-1}\right)^{\frac{1}{2}}=\left(P_{x}^{t} \times \frac{P_{x+1}^{t}}{{ }_{1} S_{x}}\right)^{1 / 2}
$$

where $P$ and $S$ respectively denote the census population counts and the ASSA model survival factors. The probability of dying between birth and before reaching their fifth birthdays, $5 \mathrm{q} 0$ is then calculated as where $4 \mathrm{ql}$, the probability of dying between age I but before reaching the fifth birthday is calculated from the central mortality rates using

$$
{ }_{4} q_{1}=1-\exp \left(-\int_{1}^{4} \mu(x) d_{x}\right) \approx 1-\exp \left(-\sum_{x=1}^{4}{ }_{1} M_{x}\right)
$$

where $\mu(x)$ is the actual force of mortality approximated by the central mortality rate, IMx. Note that in the calculation of ${ }_{1} M_{x}$, it is assumed that those who die between ages $x$ and $x+1$ do so halfway between the census date and one year before the census date.

In addition to the national estimate, infant and U5M rates for each of the nine provinces of South Africa are computed following the same procedure except that instead of the national level survival factors, provincial survival factors are used from the ASSA model in order to get the respective estimates of the number of children exposed to the risk of death between age $x$ and $x+I$ for $x=1,2,3,4$ and in each province.

However, for municipal-level estimates a different approach is implemented as it is not feasible to follow the same procedure as the national or provincial level estimates. First, it is assumed that the ratio of U5M to infant mortality rate in each municipality is the same as the ratio at the respective province and hence the U5M rates are computed by multiplying the infant-mortality rates by these factors (ratios). Second, the infant mortality rates are estimated by fitting a spatial Bayesian smoothing model using the number of infant deaths and births that occurred 12 months before the census in each municipality as inputs (as discussed in the next section). The original or crude mortality rates are used as initial values for the parameter of interest in the smoothing model during MCMC simulation. The smoothing is important because otherwise the estimates become unstable as there are fewer deaths in many municipalities and hence, a few more or less child deaths can greatly impact the estimates especially in 
less-populated municipalities. The method also helps to obtain mortality rates estimates for those municipalities which have zero observed deaths in the data.

The smoothed municipal-level infant and U5M estimates are aggregated up to give smoothed estimates of the respective rates at national and province levels. It is expected that the difference between the smoothed and unsmoothed estimates at national and province levels is very small. The real advantage of the smoothing is for the municipal-level estimates.

\section{Bayesian Spatial Smoothing Model specification}

A full Bayesian spatial smoothing method is applied to the municipal-level infant mortality rates to improve the quality of the estimates. The parameters of the prior distribution in full Bayesian smoothing are considered to be random variables with their own distributions, resulting in a hierarchical model. The first level of the model is defined by the observed data itself while in the second level the prior distribution defines spatial dependence between nearby areas through its hyper-parameters.

In this study an adjacency matrix is used to identify neighbouring areas. Neighbours are defined as municipalities that are physically connected to one another. There are 234 municipalities and I244 distinct adjacent pairs of municipalities (neighbours) in South Africa which give an average of 5.3 neighbours per municipality with the smallest number of neighbours being $I$ and the largest number of neighbours being $\mathrm{II}$.

To use prior distributions obtained from neighbouring areas, a hierarchical Bayesian model is employed in which the first level of the model consists of the level of child mortality in an area in which the number of child deaths reported in each municipality, $\mathrm{Yi}$, is modelled using a binomial distribution as given below.

$$
Y_{i} \sim \operatorname{Binomial}\left(p_{i}, n_{i}\right)
$$

where pi is the probability that a child is dying before reaching the first birthday in municipality $i$ and $n i$ is the total number of children in the municipality. The resulting fitted values of pi will be used as a smoothed estimate of infant mortality in municipality $i$. This parameter of interest is modelled using a generalised linear model:

$$
\log i t\left(p_{i}\right)=\alpha+S_{i}
$$

where $\alpha$ is an unstructured random effect representing the global mean of the log-relative risks for all areas and $\mathrm{Si}$ is a spatially structured random effect representing the municipal-specific effects or the deviation from the global mean (Lunn et al., 2013).

In order to further improve the estimates; it is a good practice to include some important determinants of child mortality in the model specified above. In this regard, two variables are included: level of females' education and the level of HIV in the municipalities. Females' education is known to be a strong predicator of child mortality in many researches. On the other hand, HIV has significantly affected the mortality of children in South Africa. Therefore, the average years of schooling of women aged 15-49 in each municipality and the provincial HIV prevalence rate among adults in the 15-49 age group are included in the model specified above. HIV prevalence rates are taken from the 2012 South African national HIV prevalence, incidence and behaviour survey conducted by the Human Science Research Council (HSRC, 20I4a). The revised generalised linear model for the probability of death controlling for these variables becomes:

$$
\log i t\left(p_{i}\right)=\alpha+\beta_{1} X_{1 i}+\beta_{2} X_{2 i}+S_{i}
$$

Where $X 1 i$ and $X 2 i$ are respectively the education and HIV variables as defined above. The inclusion of these two variables in the model helps to effectively use the spatial neighbourhood, females' education and HIV prevalence rate to predict the probability of death for each municipality.

The second level of the hierarchical Bayesian model is the prior distributions for the random effects. An improper uniform prior distribution is assigned for the unstructured random effect, $\alpha$ (Lunn et al., 20I3).

$$
\alpha \sim \text { dflat () }
$$

Since there is very little information available on how much education or HIV impact child mortality occurs in each municipality, very weak prior distributions for bl and b2 are given by assigning a small value for the precision. In doing so, the data will be guaranteed to be the main determinant of the estimates.

$$
\beta_{1 i}, \beta_{2 i} \sim N(0,0.001)
$$

The spatially structured random effect is assigned a conditional autoregressive (CAR) distribution with parameter

$$
S_{i} \sim \operatorname{CAR}(\tau)
$$

The CAR model specifies how each $\mathrm{Si}$ is related to the $\mathrm{Sj}$ at all other locations via a set of univariate conditional distributions. One of the most commonly used formulations (see Lunn, Jackson, Best et al.) which is applied in this research is 


$$
S_{i} \mid S_{\backslash i} \sim \text { Normal }\left(\sum_{j \neq i} \frac{w_{i j} S_{j}}{w_{i+}}, \frac{\tau^{2}}{w_{i+}}\right)
$$

Where wij are weights used to express spatial dependence between municipality $i$ and municipality $\mathrm{j}$, with $w_{i j}=w_{j i}, w_{i i}=0$ and $w_{i+}=\sum_{j} w_{i j}$. Usually wij is defined as $w i j=1$ if municipality $i$ and $j$ are neighbours and wij $=0$ otherwise. Thus, the conditional mean of $\mathrm{Si}$ is a weighted average of the others. This model is available in WinBUGS software, as

\section{$S[1: n] \sim$ car normal (adj]], weights[], num[], inv.tau.sqared)}

The CAR model also includes the hyper-parameter $\tau$, the precision of the variance, which denotes how similar or variable neighbouring areas should be. Due to uncertainty in the degree of similarity in neighbouring areas, in the third level of the hierarchical model, $\tau$ is assigned its own distribution, a hyper-prior distribution, with a very weak gamma distribution.

$$
\tau \sim \gamma(0.5,0.0005)
$$

To determine the standard deviation of $S, \tau$ is normally converted into the form $\varsigma . S=\sqrt{1 / \tau}$, where $w$ is scalar.

The parameters of the specified Bayesian models are estimated by the use of WinBUGS software which performs Bayesian inference based on the MCMC sampling scheme. The two models are fitted and compared with DIC (deviance information criterion). The first one is with only spatial structure, and the second model incorporating females' education and HIV prevalence rates. For each model 100000 iterations are run with the initial 10000 discarded from the use for parameter estimation. After convergence, the model with the lowest DIC is selected. Convergence is evaluated by inspecting trace and autocorrelation plots of samples for each chain, as well as other numerical summaries as shown below.

For visualisation and further ease of comparison, the estimated $U 5 M$ rates of the municipalities and provinces are mapped with GIS software. The shape files corresponding to the $201 \mathrm{I}$ census which are used for creating the maps were obtained from Municipal Demarcation Board of South Africa (MDBSA, 20I4). They are defined as the GCS WGS 1984 geographic coordinate system and adopted the Africa Albers Equal Conic Area System for projecting the final maps. These options are available in the ArcGIS software.

\section{Methods for measuring poverty and inequality}

Two methods of measuring, and one measure of inequality are considered. The measures are determined at national, provincial and municipality levels. The first poverty measurement approach is based on monthly per capita income and comparing it with the national poverty line. As this approach is not the best method to reflect the actual living standard of the population, another measure of poverty is computed by constructing an index from different indicator variables which are supposed to be related with the living standard of people in a better way. It is constructed based on various indicators of wellbeing. Factor analysis (FA) is used to construct the index. The procedure mainly involves extracting the factor(s) by partitioning the total variance in each of the variables into variances which are shared and unique variance. The detail theory and application of FA can be found in any standard multivariate text like Hair et al. (2010). The descriptions of the variables used for constructing the index including some summary statistics of the variables are shown in Table I below.

Table I Summary of variables used for LSI construction

\begin{tabular}{llcccc}
\hline Variable & Category (code) & Mean & SD & $\begin{array}{c}\text { Factor } \\
\text { loading }\end{array}$ & $\begin{array}{l}\text { Coeff- } \\
\text { icient }\end{array}$ \\
\hline \hline Dwelling Type & House (I), Other (0) & 0.66 & 0.48 & 0.384 & 0.066 \\
Room per person & Greater or equal to I (I), less than I (0) & 0.69 & 0.46 & 0.257 & 0.030 \\
Roof made of & Tiles (3), Concrete/Block (2) Other (I) & 1.98 & 0.66 & 0.43 I & 0.058 \\
Wall made of & Brick (3), Concrete/Block (2) Other (I) & 1.93 & 0.60 & 0.388 & 0.067 \\
Energy used for lighting & Electricity (I), Other (0) & 0.85 & 0.36 & 0.631 & 0.128 \\
Energy used for cooking & Electricity/Gas (I), Other (0) & 0.77 & 0.42 & 0.674 & 0.123 \\
Piped water on premises & Available (I), Not available(0) & 0.73 & 0.44 & 0.667 & 0.106 \\
Flush Toilet & Available (I), Not available(0) & 0.60 & 0.49 & 0.717 & 0.179
\end{tabular}




\begin{tabular}{llllll} 
Television & Available (I), Not available(0) & 0.76 & 0.43 & 0.595 & 0.096 \\
Satellite Dish & Available (I), Not available(0) & 0.26 & 0.44 & 0.554 & 0.092 \\
Refrigerator & Available (I), Not available(0) & 0.70 & 0.46 & 0.641 & 0.118 \\
Washing Machine & Available (I), Not available(0) & 0.32 & 0.47 & 0.645 & 0.120 \\
Vacuum Cleaner & Available (I), Not available(0) & 0.17 & 0.38 & 0.536 & 0.097 \\
Computer & Available (I), Not available(0) & 0.22 & 0.41 & 0.555 & 0.105 \\
Internet access & Available (I), Not available(0) & 0.36 & 0.48 & 0.436 & 0.057 \\
Rubbish collected by local authority & Yes (I), No(0) & 0.62 & 0.49 & 0.625 & 0.104 \\
\hline
\end{tabular}

Source: Stats SA census 20II

The first factor is enough to explain about $80 \%$ of the variance in the dataset and hence it's used to construct the index. The factor loadings and the coefficients of each variable used to generate the index are given on Table I. The constructed index is categorized into 5 quintiles which can be used as ranking the level of living standard (LS) of households. A household lying in the first quintile is categorized as to have the poorest living standard while a household lying in the fifth quintile is categorized to have the best living standard. Furthermore, households in the first two quintiles are categorized as poor and LS poverty headcount ratio (LS PHCR) is computed for each area.

Income inequality is expected to be positively correlated with child mortality as greater inequality in income within communities reflects unequal access to healthcare, nutrition and other services which is likely to reduce the health of the poor (Rodgers, 2002, Waldmann, 1992). For this purpose, Gini index (Gl) is computed for each province and municipality of the country from the distribution of their population and income class as reported in the 201 I census.

\section{Results of analysis}

Estimates of child mortality from household deaths data

Using the weighted total infant deaths and the number of births that occurred in the country one year before the census, which is calculated as I 136 387 , infant mortality rate or probability of dying before age one (Iq0) is estimated to be 37 per 1000 live births. On the other hand, the probability of dying between age one and $5(4 \mathrm{ql})$ is computed based on the method discussed in Section 3.3 and as shown in Table 2 as 13 deaths per 1000 live births. Combining the estimates of $\mathrm{Iq0}$ and $4 \mathrm{q} I$, the national estimate of $U 5 M$ rate or the probability of dying before reaching age 5 is 49 deaths per 1000 births.

Table 2 National level child mortality estimates

\begin{tabular}{|c|c|c|c|c|}
\hline Age & No of Deaths & $\begin{array}{c}\text { Average } \\
\text { Population/Births }\end{array}$ & Central Death Rate & Mortality Rates \\
\hline 0 & 42186 & I I36387 & NA & \\
\hline I & 7169 & I | 47273 & 0.0062 & $1 q_{0}=37.12$ \\
\hline 2 & 3329 & I | 47342 & 0.0029 & ${ }_{4} q_{1}=12.76$ \\
\hline 3 & 2228 & 1121930 & 0.0020 & ${ }_{5} \mathrm{q}_{0}=49.4 \mathrm{I}$ \\
\hline 4 & $|85|$ & | 08225 | & 0.0017 & \\
\hline
\end{tabular}

Applying the same procedure but by disaggregating the census data by province infant and U5M rates are estimated. These estimates are provided in Table 3 together with the smoothed estimates computed by aggregating the municipal level Bayesian estimates. The spatial distribution of U5M among the nine provinces is shown on Figure I. The map is created by categorizing the provinces into 5 classes based on the severity of their U5M rates. WC lies in the first quintile followed by GT and LP while Northern Cape (NC) seized the third quintile. KZN and FS are in the last class preceded by North West (NW), EC and MP. 
Table 3 Provincial level estimates of child mortality

\begin{tabular}{|c|c|c|c|c|c|c|c|}
\hline \multirow{2}{*}{ Province } & \multicolumn{4}{|c|}{ Direct Estimates } & \multicolumn{3}{|c|}{ Smoothed Estimates } \\
\hline & Iq0 & $5 q 0$ & $\mathrm{Iq} 4$ & $5 q 0 / / q 0$ & Iq0 & $5 q 0$ & $\mathrm{Iq} 4$ \\
\hline Western Cape & 18.86 & 24.75 & 6.00 & 1.31 & 19.86 & 26.06 & 6.33 \\
\hline Eastern Cape & 41.69 & 55.96 & 14.89 & 1.34 & 42.49 & 57.04 & 15.19 \\
\hline Northern Cape & 40.27 & 52.55 & 12.79 & 1.30 & 38.50 & 50.24 & 12.20 \\
\hline Free State & 47.82 & 68.47 & 21.69 & 1.43 & 47.61 & 68.17 & 21.59 \\
\hline KwaZulu-Natal & 49.81 & 68.78 & 19.96 & 1.38 & 51.14 & 70.61 & 20.52 \\
\hline North West & 44.98 & 61.79 & 17.60 & 1.37 & 45.15 & 62.03 & 17.67 \\
\hline Gauteng & 25.95 & 36.07 & 10.40 & 1.39 & 26.75 & 37.19 & 10.73 \\
\hline Mpumalanga & 41.29 & 58.13 & 17.57 & 1.41 & 42.51 & 59.85 & 18.11 \\
\hline Limpopo & 28.37 & 39.27 & 11.22 & 1.38 & 28.87 & 39.98 & 11.43 \\
\hline ZA & 37.12 & $49.4 I$ & 14.09 & 1.34 & 36.03 & 49.95 & 14.45 \\
\hline
\end{tabular}

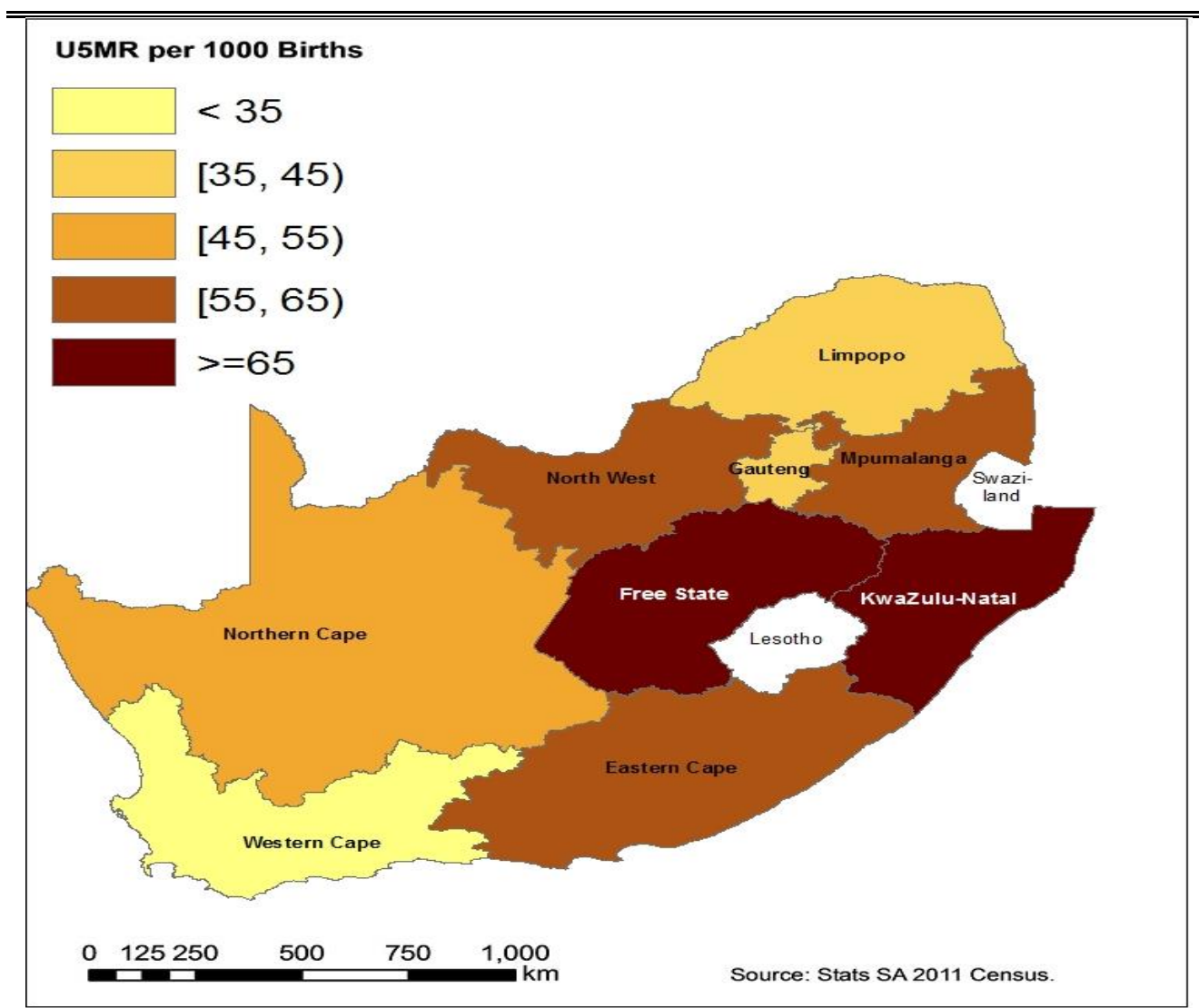

Figure I Provincial smoothed estimates of U5M rate

Computing direct estimates of U5M at municipal levels using the same procedure, however, is problematic as the number of deaths at municipallevel are very small in many municipalities to generate stable estimates. First, stable estimates of infant mortality rate for each municipality are computed using Bayesian spatial smoothing technique. Second, it is assumed that the ratio of U5M rate to infant mortality rate in each municipality within a province is the same as the ratio of the two quantities at the respective province. These ratios for each province are as shown in Table 3, which ranges from 1.3 in $\mathrm{NC}$ to $\mathrm{I} .43$ in FS.

Spatially smoothed municipal-level Bayesian estimates of child mortality

Two different Bayesian models are compared. The first model (Model-I) is only with spatial smoothing pure conditional autoregressive (CAR) model while the second one (Model-2) incorporates municipal level mean years of women education and provincial HIV prevalence rate for adults aged 15-49. After 
running each of the models initially for 10000 iterations and another 100000 iterations for monitoring stage, the respective models have returned DIC values of II87.I, and II64.7 respectively. Hence, the improved model (Model-2) is better to estimate municipal-level child mortality rates. The model is then used to generate estimates of infant and U5M rates to each municipality. The inclusion of the two variables in the CAR model has improved the estimates to some extent. This can be demonstrated by looking at the relationship between the U5M estimates and the variables included as indicated in the plots shown in Figure 2 and 3 below.

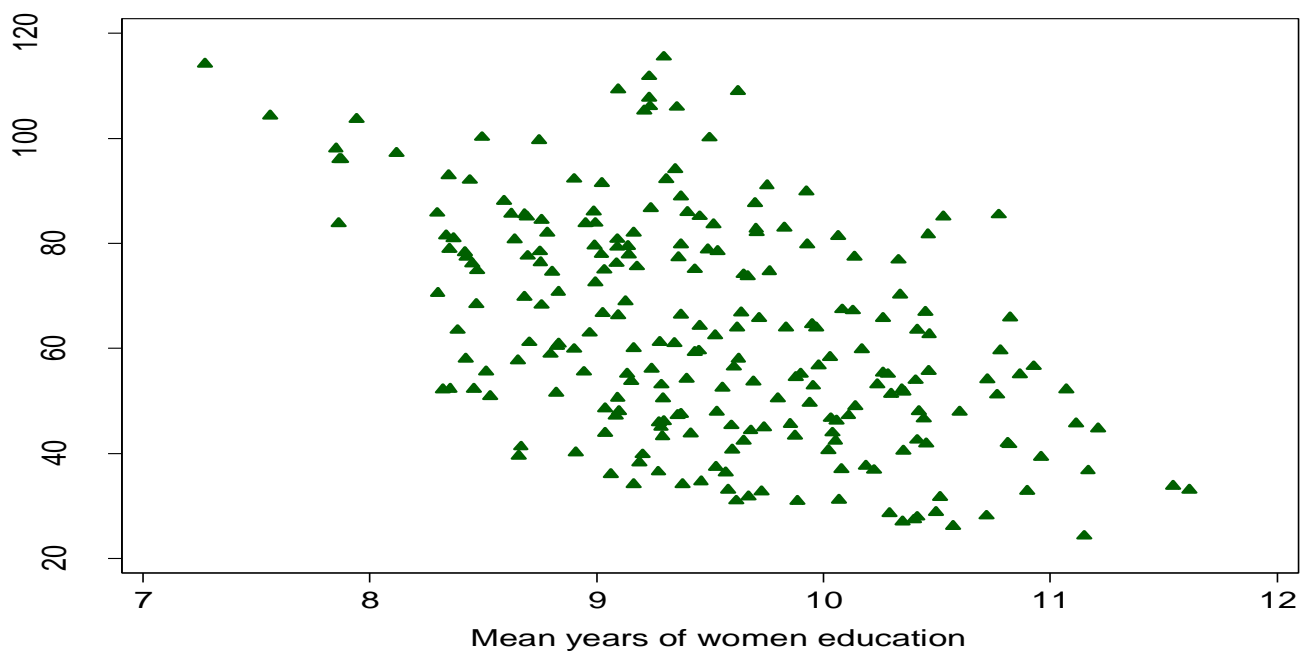

Figure 2 U5M rate and mean years of mothers' education

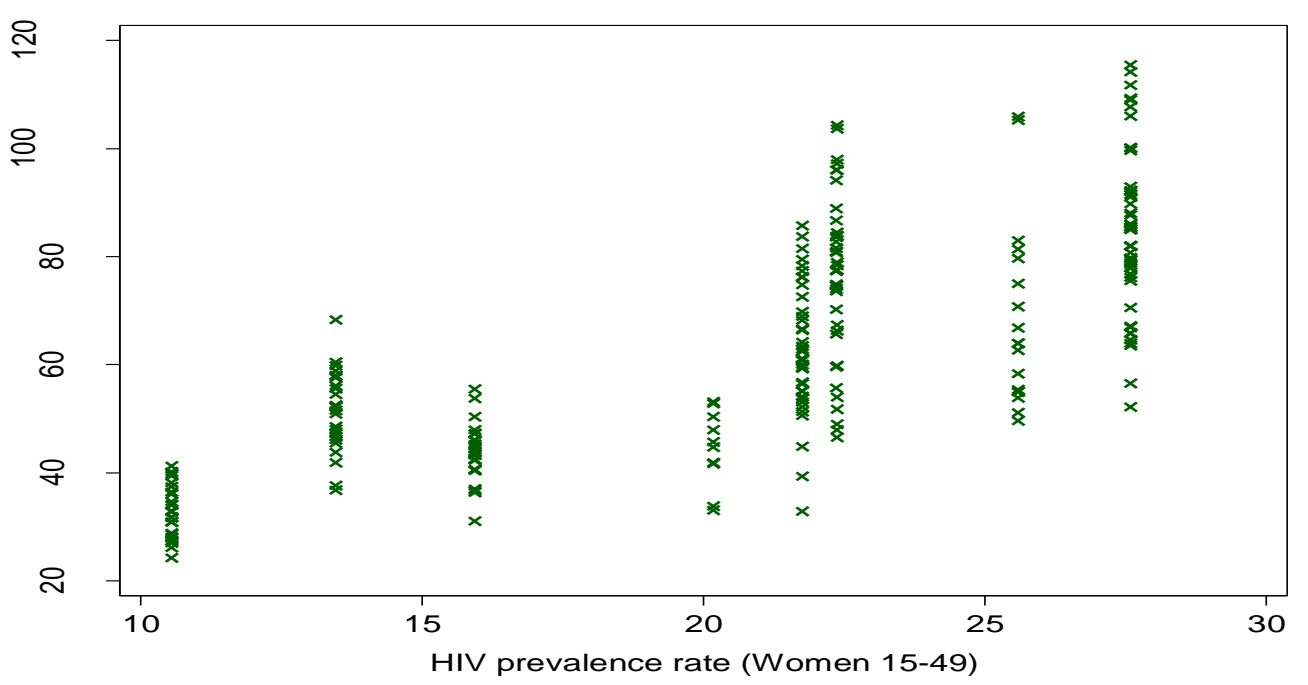

Figure 3 U5M rate vs HIV prevalence rate

Estimates of municipal level infant and child mortality rates

The final municipal level estimates of infant and U5M rates are provided together with other relevant statistics in the appendix (Table 9). The municipalities in the table are ranked based on their level of U5MR. In addition, the estimates of child mortalities are associated with geo-referenced data of the municipalities and mapped as shown on Figure 4. The map helps one to see the spatial patterns of child mortality in the country in that mortality is heavier in north-east, central and north-west part and lighter in south-east and northern parts of the country. Among all the municipalities, City of Cape Town (CCPT) has got the minimum U5M of 24.0 deaths per 1000 live births while uPhongolo of the KwaZulu-Natal province has recorded the maximum rate of 109.1 which is about 4.6 times higher than the mortality rate of CCPT. This implies that the probability that a child who is born in uPhongolo is 4.6 times more likely to die before reaching its fifth birthday than a child who is born in CCPT. 
For such ease of comparisons, the U5M rate estimates of all municipalities are divided by the minimum U5M rate (CCPT) in order to get a kind of standardised mortality index (SM). These indices and the corresponding U5M ranks for each of the municipalities are also given in Table 9. From this table one can appreciate the degree of differential of child mortality among municipalities in South Africa.
In the time period where the mortality estimate applies, the U5M rate of $60 \%$ of the municipalities is more than twice the mortality rate of the city of Cape Town. Furthermore, in $30 \%$ of the municipalities, child mortality is three times higher while in $7 \%$ of the municipalities the mortality is four times higher than the mortality in CCPT.

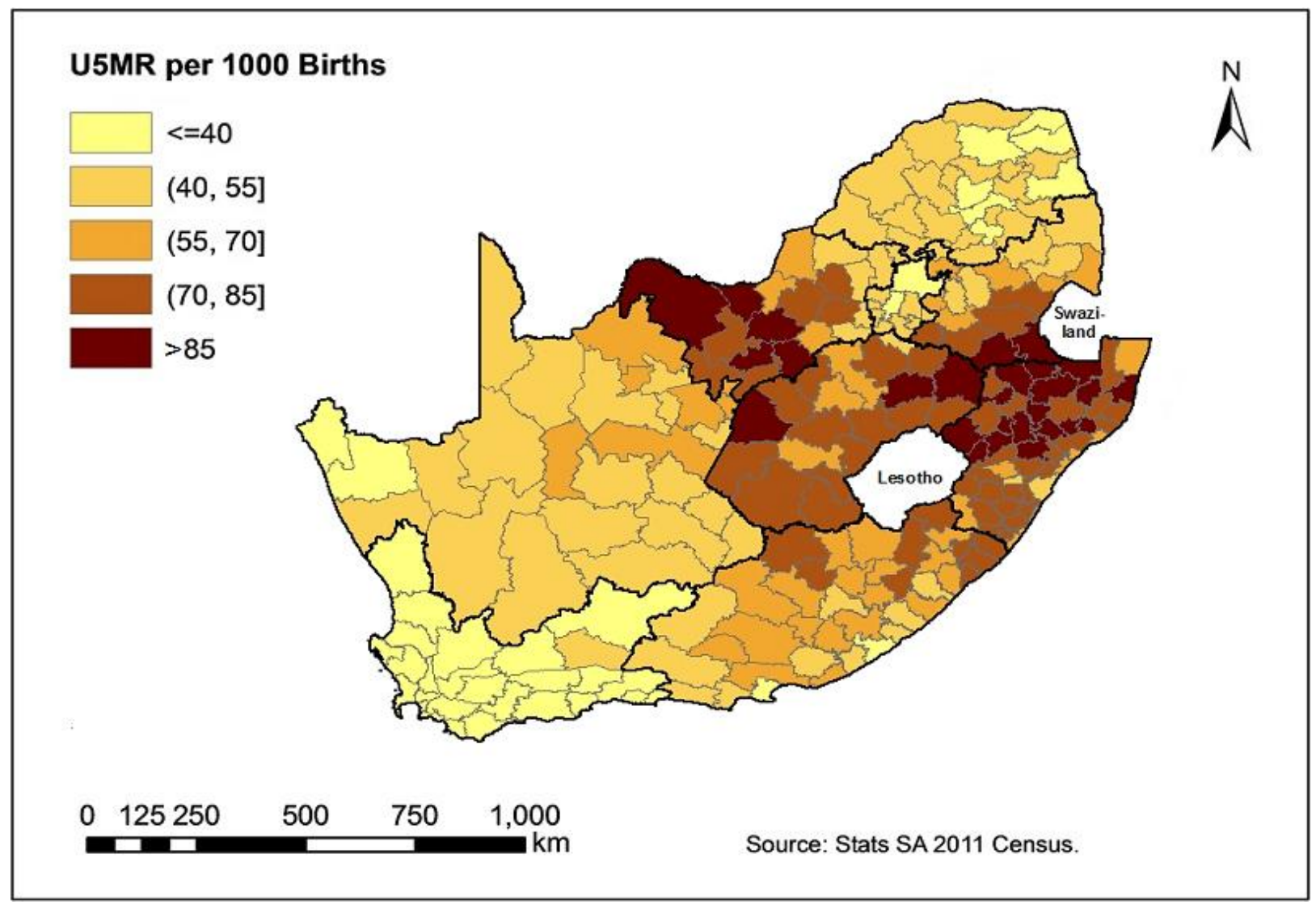

Figure 4 Spatially smoothed municipal-level estimates of U5MRs

There are clear and consistent evidences of elevated mortality levels in municipalities in KwaZulu-Natal and North West and lowest levels in municipalities of the Western Cape, Gauteng and Limpopo. Summary statistics of municipal-level U5M estimates in each province are given on Table 4. The information in the table together with the map helps to appreciate not only the magnitude of child mortality in the municipalities within provinces but also the degree of variation in mortality in each of the provinces. The greatest disparity in child mortality among municipalities is observed in North-West and Mpumalanga provinces with a CV of 25 and $24 \%$ respectively. The municipalities in Limpopo province, on the other hand, have the lowest variation in child mortality that they are the most alike relative to municipalities in other provinces. Nationwide, the 234 municipalities vary in child mortality by $33 \%$ while the mean and median values are 61 and 62 respectively. The box plots in Figure 5 present the combined information of extent and disparity of the mortalities each province. 
Table 4 Summary Statistics of U5MR Municipal-level estimates

\begin{tabular}{lrrrrrrr}
\hline \multicolumn{1}{c}{ Province } & $\mathbf{n}$ & \multicolumn{1}{c}{ Mean } & \multicolumn{1}{c}{ Median } & \multicolumn{1}{c}{ Min } & \multicolumn{1}{c}{ Max } & \multicolumn{1}{c}{ SD } & CV \\
\hline \hline Western Cape & 39 & 32.28 & 32.18 & 23.97 & 40.41 & 4.72 & 14.61 \\
Eastern Cape & 20 & 60.99 & 59.31 & 32.28 & 82.18 & 11.26 & 18.46 \\
Northern Cape & 10 & 50.10 & 50.82 & 36.13 & 66.07 & 6.89 & 13.74 \\
Free State & 51 & 74.67 & 74.46 & 54.14 & 91.57 & 9.45 & 12.66 \\
KwaZulu-Natal & 25 & 81.09 & 81.54 & 50.80 & 109.08 & 13.60 & 16.77 \\
North West & 18 & 72.28 & 75.43 & 45.51 & 99.06 & 18.28 & 25.29 \\
Gauteng & 27 & 43.51 & 44.18 & 32.48 & 51.71 & 6.79 & 15.61 \\
Mpumalanga & 19 & 66.27 & 61.93 & 48.39 & 100.51 & 15.70 & 23.69 \\
Limpopo & 25 & 42.76 & 42.90 & 30.60 & 53.97 & 5.12 & 11.97 \\
\hline ZA & 234 & 60.84 & 61.55 & 23.97 & 109.08 & 19.79 & 32.52 \\
\hline \hline
\end{tabular}

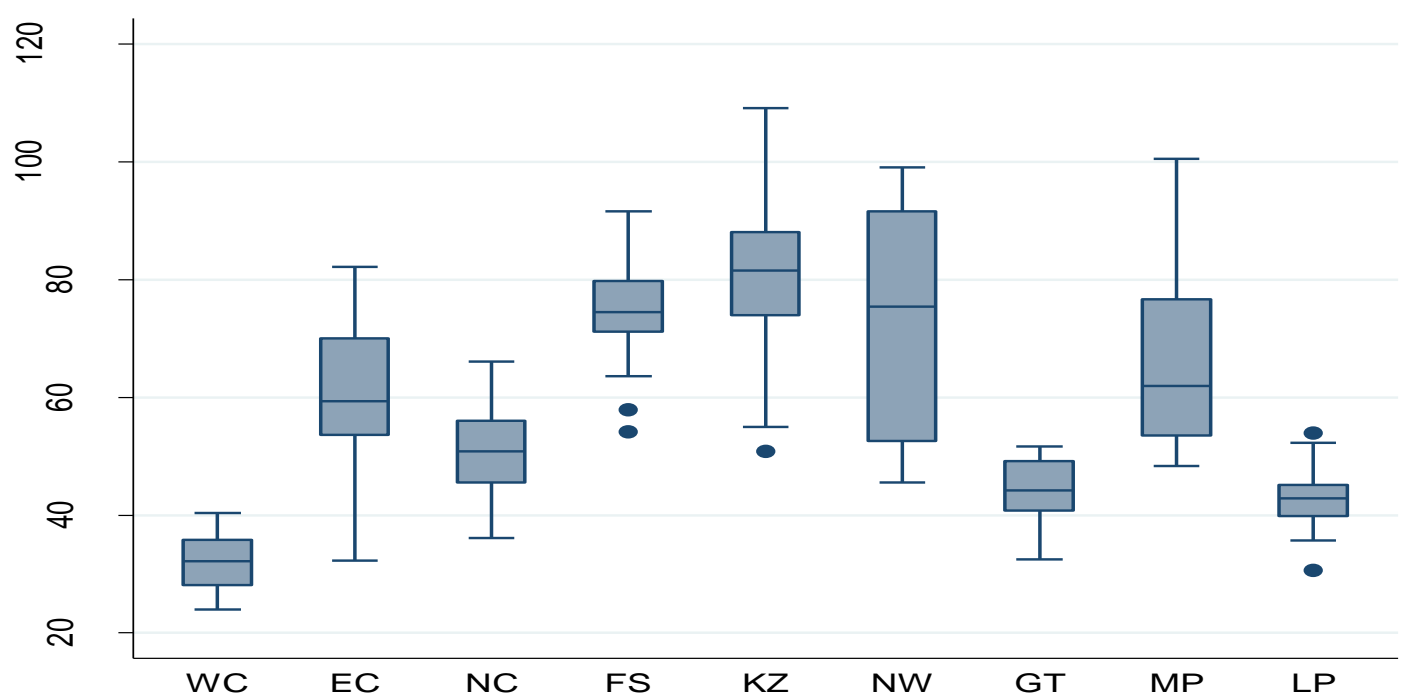

Figure 5 Distribution of municipal level estimates of U5MR among the provinces

Estimates child mortality in relation to poverty and inequality

The proportion of poor people at national level is estimated to be about $40 \%$ both in terms of income and LS index while income inequality as measured by Gini index is 0.72 . In order to understand the relationships at province level, Table 5 explicitly presents the information for each province. There are large differences in poverty among the provinces which range from 30 to $54 \%$ in terms of income and from 18 to $69 \%$ in terms of LS index while the variation in inequality is very low. These economic disparities can be compared with health differentials as measured by U5M rates (26-7I deaths per 1000 births). Western Cape (WC) has not only registered the lowest child mortality rate but also had the smallest measures of poverty and inequality. It is only $18 \%$ of the people living in the province that are classified as poor in terms of LS as compared to $30 \%$ based on per capita monthly income. On the other hand, KwaZulu-Natal (KZN), stands but third and second from the last in terms of poverty and inequality respectively. Limpopo and Eastern Cape (EC) are the first and second poorest provinces based on both measures of poverty while EC seemed to be relatively the most unequal province, followed by KZN. It is apparent that Limpopo is the only province which had lower mortality rate unlike its higher level of poverty in both dimensions considered in this research. 
Table 5 Estimates of U5MR, poverty and inequality at province level

\begin{tabular}{lcccc}
\hline \multicolumn{1}{c}{ Province } & U5MR & PHCR (Income) & PHCR (LS Index) & Gini Index \\
\hline \hline Western Cape & 26.06 & 30.22 & 18.06 & 0.677 I \\
Eastern Cape & 57.04 & 53.06 & 58.83 & 0.7243 \\
Northern Cape & 50.24 & 40.38 & 36.39 & 0.7054 \\
Free State & 68.17 & 42.92 & 30.33 & 0.7022 \\
KwaZulu-Natal & 70.61 & 48.66 & 52.06 & 0.7164 \\
North West & 62.03 & 43.87 & 50.03 & 0.6790 \\
Gauteng & 37.19 & 31.59 & 20.77 & 0.6824 \\
Mpumalanga & 59.85 & 45.73 & 48.65 & 0.7071 \\
Limpopo & 39.98 & 54.34 & 68.79 & 0.7174 \\
\hline ZA & 49.95 & 40.73 & 40.22 & 0.7156 \\
\hline \hline
\end{tabular}

Note: U5MR is per thousand while PHCRs are expressed as percentages

The estimates of poverty and inequality for the 234 municipalities are also computed and are given together with the smoothed estimates of U5M rates and other related statistics in Table 9. It is evident that in most cases both measures of poverty are positively related with child mortality. It must be noted that the poverty measure computed based on the LS index has shown a stronger association with child mortality- correlation coefficient of 0.573 , than the poverty measures computed based on per capita income alone - correlation coefficient of 0.475 . In both measures, however, there are many exceptions in that lower poverty does not necessarily guarantee lighter mortality and vice versa. For instance, although Thulamela, a municipality in Limpopo province, is ranked as the 195 th and $184^{\text {th }}$ poor municipality in terms of income and living standard respectively, it has recorded the $13^{\text {th }}$ lighter U5M rate. Similarly, Mutale, another municipality in Limpopo, has the $23^{\text {rd }}$ smallest U5M while respectively scoring a rank of 206 and 208 in terms of income and living standard poverty. On the other hand, municipalities like Mpofana (in KZN province) with income poverty rank of 75th and Maquassi Hills (in NW province) with living standard poverty rank of 93 had registered among the highest mortality rates with ranks of $198^{\text {th }}$ and $224^{\text {th }}$ respectively.

The relationship between income inequality and child mortality, however is not as strong as the relationship between child mortality and poverty. In general, all municipalities experienced a very high level of inequality, Gini index ranging from 0.576 in Ngqushwa (in EC province) to 0.784 in Jozini (in KZN province) and $79 \%$ of all the 234 municipalities scoring a Gini index greater than 0.65 . Nonetheless, there is a weak positive correlation, , between income inequality and child mortality implying that on average there are more deaths in municipalities where the people are more unequal in terms of income than in municipalities with less unequal people. However, it is not surprising that there are inverse relationships between income inequality and child mortality in many municipalities including Nqutu and Dannhauser (both in KZN) with much lower inequality and higher mortality, and Knysna and Bitou (both in WC) with much higher inequality but lower mortality.

For a better understanding of the relationship among child mortality, poverty and inequality, municipalities are divided into poverty and inequality quintiles and the corresponding average U5M rates are then computed in each quintile. This information is provided below in Table 6. In each of the three cases, an increasing trend of child mortality is observed along the quintiles, confirming that on average an increase in poverty and inequality is associated with an increase in mortality of children. However, the magnitude of the changes in mortality along the quintiles of income inequality (Gini Index) are smaller, which supports the points raised above that child mortality has stronger association with income and living condition than income inequality. 
Table 6 U5M rates under poverty and inequality quintiles

\begin{tabular}{|c|c|c|c|}
\hline \multirow[b]{2}{*}{ Quintiles } & \multicolumn{3}{|c|}{ Mean U5MR in Quintiles of } \\
\hline & PHCR (income) & PHCR (LS index) & Gini Index \\
\hline QI & 42.77 & 44.00 & 54.99 \\
\hline Q2 & 53.41 & 57.43 & 58.40 \\
\hline Q3 & 65.51 & 63.32 & 59.25 \\
\hline Q4 & 67.87 & 66.10 & 61.08 \\
\hline Q5 & 74.97 & 73.64 & 70.72 \\
\hline Corr coefficient & 0.4749 & 0.5727 & 0.2706 \\
\hline
\end{tabular}

Table 7 presents the poverty and inequality measures for the top and last 15 municipalities according to the child mortality rankings and their corresponding ranks in in poverty and inequality. The top 15 best municipalities have recorded an average U5M rate of 28.8 per thousand as opposed to 100.6 by the bottom 15 municipalities. If one is interested to compare these results with the average measures of poverty and inequality, the mean income poverty head-count ratios are $31 \%$ and $61 \%$ respective for the first 15 and the last 15 municipalities while the mean living standard poverty head-count ratios are 23 and 76. The measure of income inequality has resulted in a mean value of 0.67 and 0.70 respectively for the top 15 and bottom 15 municipalities. This confirms that child mortality is heavier in municipalities where poverty and inequality are worse, and that the association is weaker with inequality.

Table 7 I 5 best and worst municipalities in terms of U5M and their rankings in poverty and inequality

\begin{tabular}{|c|c|c|c|c|c|c|c|c|c|c|c|}
\hline \multirow[b]{2}{*}{ Municipality } & \multirow[b]{2}{*}{ Province } & \multirow[b]{2}{*}{ U5MR } & \multicolumn{3}{|c|}{ Ranks } & \multirow[b]{2}{*}{ Municipality } & \multirow[b]{2}{*}{ Province } & \multirow[b]{2}{*}{ U5MR } & \multicolumn{3}{|c|}{ Ranks } \\
\hline & & & PHCR & $\begin{array}{c}\text { LS } \\
\text { PHCR }\end{array}$ & GI & & & & PHCR & $\begin{array}{c}\text { LS } \\
\text { PHCR }\end{array}$ & GI \\
\hline City of Cape Town & WC & 23.97 & 33 & 14 & 86 & uPhongolo & $\mathrm{KZN}$ & 109.08 & 171 & 170 & 214 \\
\hline Mossel Bay & WC & 25.80 & 48 & 3 & 55 & Msinga & $\mathrm{KZN}$ & 107.91 & 228 & 231 & 76 \\
\hline Knysna & WC & 26.62 & 52 & 60 & 170 & eDumbe & $\mathrm{KZN}$ & 105.77 & 197 & 169 & 88 \\
\hline Overstrand & WC & 26.97 & 40 & 25 & 47 & Emadlangeni & $\mathrm{KZN}$ & 103.53 & 144 & 158 & 59 \\
\hline Bitou & WC & 27.48 & 72 & 46 & 176 & Abaqulusi & $\mathrm{KZN}$ & 103.26 & 163 & 135 & 227 \\
\hline Stellenbosch & WC & 27.69 & 44 & 24 & 104 & Okhahlamba & $\mathrm{KZN}$ & 102.08 & 220 & 199 & 201 \\
\hline George & WC & 28.19 & 38 & 20 & 52 & Nqutu & $\mathrm{KZN}$ & 100.60 & 227 & 197 & 10 \\
\hline Drakenstein & WC & 28.38 & 23 & 7 & 75 & Mkhondo & MP & 100.51 & 166 & 149 & 148 \\
\hline Breede Valley & WC & 30.40 & 27 & 43 & 50 & Pixley Ka Seme & MP & 99.89 & 157 & 116 & 234 \\
\hline Theewaterskloof & WC & 30.48 & 21 & 28 & 42 & Ratlou & NW & 99.06 & 201 & 212 & 102 \\
\hline Thulamela & LP & 30.60 & 195 & 184 & 123 & Maquassi Hills & NW & 98.44 & 161 & 93 & 230 \\
\hline Saldanha Bay & WC & 31.18 & 19 & 1 & 26 & Mthonjaneni & $\mathrm{KZN}$ & 95.34 & 143 & 181 & 51 \\
\hline City of Tshwane & GT & 31.29 & 24 & 31 & 68 & Nongoma & $\mathrm{KZN}$ & 95.24 & 223 & 209 & 128 \\
\hline City of Johannesburg & GT & 32.18 & 34 & 15 & 146 & Indaka & $\mathrm{KZN}$ & 94.81 & 234 & 179 & 32 \\
\hline Nelson Mandela Bay & $\mathrm{EC}$ & 32.28 & 104 & 11 & 144 & Tokologo & FS & 93.34 & 189 & 193 & 205 \\
\hline
\end{tabular}

\section{Discussions and conclusion \\ Discussion of results}

Although child mortality in South Africa has improved substantially in the last decade, after some period of reversal mainly due to HIV, the level is much higher than the mortality in many other countries with similar economic development level. We believe that, in order to effectively address the problem and work towards further reductions of child mortality in the country it is essential that the efforts be focused more on lower administrative levels as opposed to concentrating only on the level of mortality at 4387 national level (Freedman et al., 2005). Hence, for these efforts to move forward, constructing reliable estimates of child mortality for small geographical areas should be considered as one of the first important steps. Consequently, the overall objective of this research was to produce estimates of child mortality rates for the provinces and municipalities of South Africa using the 201I census data and assess the differentials in relation to the level of poverty and inequality. In addition, studying the factors associated with child mortality in South Africa considering the hierarchical structure of the data and with special http://aps.journals.ac.za 
emphasis on poverty and inequality was the second main objective. In this chapter an attempt will be made to discuss the extent at which these objectives have been met. This involves discussing the reasonableness of the estimates of child mortality produced at national, provincial and municipal level and the validity of the results obtained on factors affecting child survival in comparison with other studies.

Estimates of infant and U5M rates at national and province level are generated directly using household death data from the $201 \mathrm{I}$ census. However, in attempting to estimate child mortality for smaller geographical areas it is often difficult to construct accurate estimates because population sizes also tend to be relatively small, resulting in unstable estimates. One common approach that would help us to overcome this issue is to use Bayesian smoothing method. Hierarchical Bayesian model has been used to construct spatially smoothed estimates of child mortality for the municipalities of South Africa. The first level of the model uses the household mortality data from the 201 I South African census while in the next level the probability of a child dying before reaching age one is modelled using a binomial model with a spatially structured random effect. The prior distribution for this random effect is constructed using a conditional autoregressive (CAR) model which incorporates spatial dependence among neighbouring municipalities and allows for its impact to be greater for municipalities with more unstable data. The estimates are further improved by incorporating average years of women's education of each municipality and the provincial HIV prevalence rates of adults aged 15-49. It is assumed that the ratio of U5M rate and infant mortality rate be the same at province level which helps us to get estimates of U5M rates for the municipalities from the infant mortality rates obtained from the Bayesian spatial smoothing model.

Having derived child mortality rates, the first important question has to be how the estimates are compared with those presented elsewhere. In this regard, the national level estimates can be compared with reports from Stats SA, Rapid Mortality Surveillance (RMS), ASSA model 2008, UN InterAgency Group for Mortality Estimation (IGME), world population prospectus (WPP) and the Institute for Health Metrics and Evaluation (IHME). Figure 6 presents the estimates of infant and U5M rates from these institutions as well as the estimates from this research and estimates from a recently published paper by Udjo (20I4). Given the degree of controversy about estimates of child mortality in South Africa and the fact that each of the institutions might have used different approaches and data sources to derive their corresponding values, it is fair to say that the estimates from this research are quite reasonable and consistent with most of these estimates. Relatively, both infant and U5M rates from RMS are lower than the others, for instance they are less by 29 and $25 \%$ compared to our estimates, while those from Stats SA seem to be a bit inflated. Despite these, the estimates from Udjo (20l4) are found to be highly exaggerated compared to the estimates from this research as well as the estimates from all other sources. It is very hard to have an infant and U5M rates of 60 and 80 per 1000 respectively for South Africa in $201 \mathrm{I}$ unless there is some problem with the data used or the method of estimation applied.

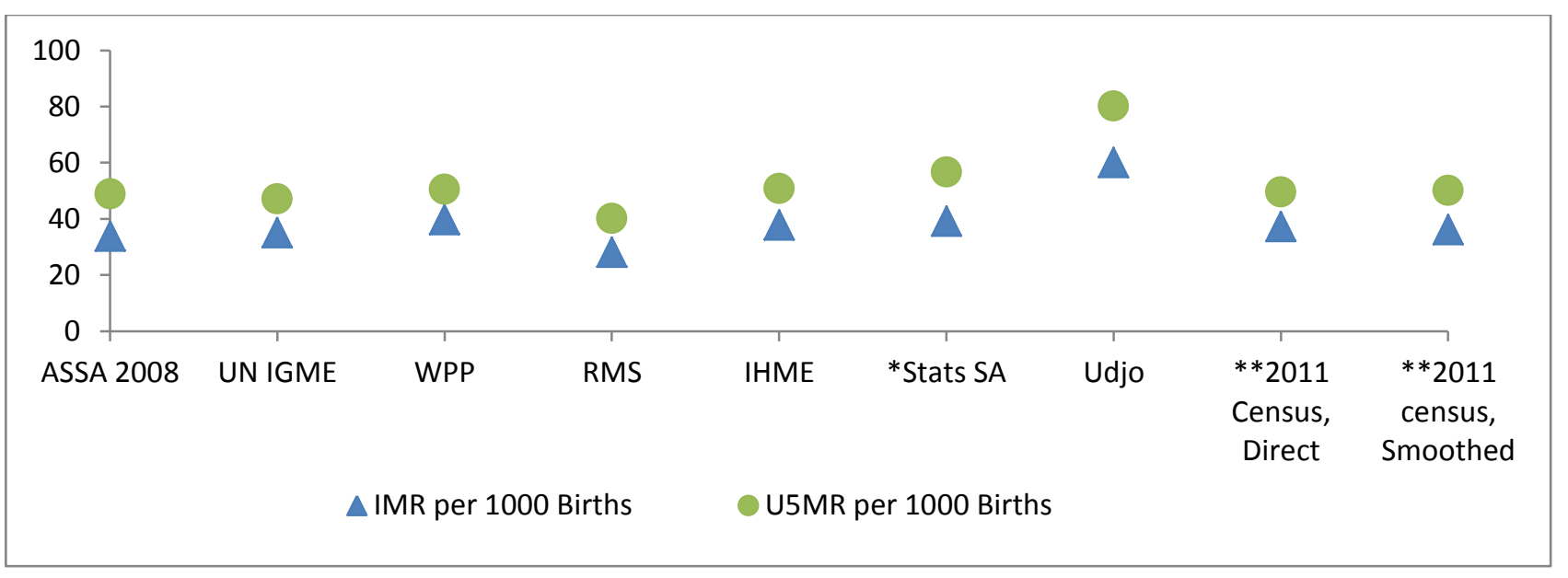

Figure 6 Comparisons of national level IM and U5M rates from various sources

Note: *Stats SA estimates refer to 2010 while others apply to 2011 ; **According to this research computation

Another way of evaluating the quality of municipal level estimates is to compare the robustness of the estimates with the crude estimates and smoothed but http://aps.journals.ac.za not improved by women education and HIV prevalence rate. Table 8 describes some summary statistics concerning these estimates. It is evident 
from the table that the Bayesian method has produced more stable and accurate results compared to the crude estimates as they have smaller variation. On the other hand, incorporating women education and HIV prevalence rate into the hierarchical Bayesian model has very little impact on the overall estimates. However, the real benefit of this adaptation can be felt in individual municipalities whose level of education and HIV prevalence differ from those of nearby municipalities. In such cases, by incorporating these two variables into the construction of estimates of child mortality, these differences are recognised and more reliable estimates can be obtained. The correlations between the two covariates and child mortality rates are much stronger in the case of the Bayesian estimates than the crude rates. It is also very important to note that there are II municipalities with missing crude estimates of child mortality, but there are no municipalities with missing Bayesian estimates of child mortality. The general approach was also used by McKinnon (2010) to find U5M rates for the municipalities of Brazil and it can be observed that our results are similar in that the use of Bayesian smoothing together with women education has improved the estimates reasonably.

Table 8 Summary statistics estimates of U5M rates at municipal-level

\begin{tabular}{lrrr}
\hline \multicolumn{1}{c}{ Statistic } & \multicolumn{1}{c}{$\begin{array}{c}\text { Crude } \\
\text { estimates }\end{array}$} & $\begin{array}{c}\text { Bayesian-Spatial } \\
\text { only }\end{array}$ & $\begin{array}{c}\text { Bayesian-with Education } \\
\text { and HIV }\end{array}$ \\
\hline \hline No of municipalities & 223 & 234 & 234 \\
Mean & 64.55 & 59.48 & 60.84 \\
Median & 57.41 & 57.44 & 58.18 \\
SD & 31.57 & 19.49 & 19.79 \\
CV (\%) & 48.90 & 32.77 & 32.52 \\
Minimum & 8.72 & 24.64 & 23.97 \\
Maximum & 200.31 & 118.23 & 109.08 \\
Correlation with Education & -0.34 & -0.38 & -0.51 \\
Correlation with HIV & 0.40 & 0.72 & 0.76 \\
Missing municipalities & $1 \mathrm{I}$ & 0 & 0 \\
\hline \hline
\end{tabular}

The child mortality differentials are believed to be highly associated with the level of poverty and inequality. Poverty in this research is measured both using income and LS. Income poor people are those who earn an average monthly household per capita income of less than R5I5 while LS based poor are those whose LS index lie either on the first or second quintile. The estimates of poverty are quite reasonable compared to Stats SA estimates (StatsSA, 20I4b). For instance, Stats SA has estimated the percentage of people living under poverty line of R443 to be $32.3 \%$ while our estimate is 4 I percent at R5 I 5 poverty line.

The proportion of poor people in provinces and municipalities are positively correlated, as expected, with the level of mortality - $95 \%$ significant correlation coefficients of 0.49 and 0.58 respectively for income and LS dimension of poverty. However, there are some exceptions in that higher poverty does not necessarily imply higher child mortality and vice-versa. Many municipalities in Limpopo province including Thulamela and Mutale, for example, have scored lower mortality rates although the levels of poverty remain very high in both dimensions of poverty. This may suggest that socioeconomic differentials are not the sole determinants of child mortality but a combination of many other factors too.

Having used the Gini coefficient as a measure of the level of income distribution with in provinces and municipalities, it is also found that income distribution is associated positively with child mortality. However, the degree of association is weak relative to that of poverty resulting in only a 0.17 significant correlation coefficient at municipal-level - significant at $95 \%$ level of confidence.

\section{Conclusions}

The study primarily aimed to derive up-to-date estimates of child mortality for the municipalities and provinces of South Africa using the 201 I census data. This is achieved through the use of direct synthetic cohort and Bayesian spatial smoothing methods. It is revealed particularly that child mortality estimation at municipal level is possible which has never been attempted so far to the best of our knowledge. Clear and significant spatial differentials in child mortality are observed in the country - at province level, U5M rate ranges from 26 deaths per 1000 births in Western Cape to 7I deaths per 1000 births in KwaZulu-Natal province, while at municipality level, it ranges from 24 deaths per 1000 births in the City of Cape Town to as high as 109 deaths per 1000 
births in uPhongolo. Furthermore, the estimates obtained are reasonable and, those at national and province level are in agreement with results from many other researches.

The study also aimed to find out how the spatial differentials in child mortality in the country are associated with the level of poverty and inequality. For this purpose, poverty in income and living standard dimensions and the Gini index are computed for each municipality as well as for the provinces and the country using data from the same census. The results show that in fact child mortality is higher in municipalities which are poorer, although there are some cases where inverse relationship is observed like several municipalities in Limpopo province that though the level of poverty is very high, child mortality is much lower in comparison with many other municipalities. It is also shown that the distribution of income similarly matters to some extent as greater child mortality is observed in areas which are more unequal although the degree of association is not as strong as with that of poverty.

Unlike its economic development status and despite policies put in place for reduction of child mortality in the country, South Africa's child mortality rate is still high as compared to other countries with similar economic development status. This research has claimed that one approach to bring better outcomes in the reduction is to address the issues at lower administrative level and has tried to provide the evidences gained from the latest available census data. The results obtained may help the government to implement policies more effectively and make more focused decisions towards better reduction of child mortality in the country.

\section{References}

ASSA 2010. Actuarial Society of South Africa 2008 AIDS and Demographic Models. Actuarial Society of South Africa.

BANGHA, M. W. \& SIMELANE, S. 2008. Spatial Differentials in Childhood Mortality in South Africa: Evidence from the $200 \mathrm{I}$ Census. African Population Studies, 22.

DORRINGTON, R., TIMAEUS, I. M., MOULTRIE, T. \& NANNAN, N. 2004. Estimates of provincial fertility and mortality in South Africa, 1985-1996. South Africa Journal of Demography, 9, 25-57.

FREEDMAN, L. P., WALDMAN, R. J., PINHO, H. D., WIRTH, M. E., CHOWDDHURY, A. M. R. \& ROSENFIELD, A. 2005. Who's got the power? Transforming health systems for women and children: Achieving the Millennium Development Goals. In: STERLING, V. (ed.) Earthscan.
HAIR, J., BLACK, C., BABIN, J. \& ANDERSON, E. 20 10. Multivariate Data Analysis, Pearson Prentice Hall.

HSRC 20I4a. South African National HIV Prevalence, Incidence and Behaviour Survey. Human Science research Coucil.

HSRC 20I4b. State of Poverty and its Manifestations in the Nine Provinces of South Africa. Economic Performance and Development. Human Science Research Council.

IGME 20I3. Levels and trends in child mortality. In: DANZHEN YOU, P. B., JINGXIAN WU AND TESSA WARDLAW (ed.). UN Inter-agency Group for Child Mortality Estimation.

KABIR, A., ISLAM, M. S., AHMED, M. S. \& BARBHUIYA, K. M. A. 200I. Factors influencing infant and child mortality in Bangladesh: Research paper. The Sciences, I, 292-295.

LUNN, D., JACKSON, C., BEST, N., THOMAS, A. \& SPIEGELHALTER, D. 2013. The BUGS Book: A practical Introduction to Bayesian Analysis, NW, CRC Press. Taylor \& Francis Group.

MCKINNON, S. A. 20I0. Municipality-level estimates of child mortality for Brazil: A new approach using Bayesian Statistics PhD, University of Texas at Austin.

MDBSA 20I4. Shapefiles for South Africa Provincies and Municipalities. Municipal Demarcation Board of South Africa.

NANNAN, N., DORRINGTON, R., LAUBSCHER, R., ZINYAKATIRA, N., PRINSLOO, M., DARIKWA, T., MATZOPOULOS, R. \& BRADSHAW, D. 2012. UNDER-5 MORTALITY STATISTICS IN SOUTH AFRICA: Shedding some light on the trend and causes 1997-2007. South African Medical Research Council, Burden of Disease Research Unit.

REIDPATH, D. D. \& ALLOTEY, P. 2003. Infant mortality rate as an indicator of population health. J Epidemiol Community Health, 57, 344-346.

RODGERS, G. B. 2002. Income and Inequality as determinants of mortality: an international crosssection analysis. International Journal of Epidemiology, 3I, 533-538.

SARTORIUS, B. K., SARTORIUS, K., CHIRWA, T. F. \& FONN, S. 20II. Infant mortality in South Africa - distribution, associations and policy implications, 2007: an ecological spatial analysis. International Journal Health Geographics, 10.

STATSSA 2014a. 201I South African census 10 percent Sample Metadata. Pretoria: Statistics South Africa.

STATSSA 2014b. Poverty trends in South Africa: An examination of absolute poverty between 2006 and $20 \mathrm{II}$. 
UDJO, E. O. 20I4. Estimating demographic parameters from the 20II South Africa population census. African Population Studies, 28, 564-578.

UNICEF 2013. South Africa 2012 Annual Report. UNICEF.

WALDMANN, R. J. 1992. Income Distribution and Infant Mortality. The Quarterly Journal of Economics, 107, I283-I302.
WHITING, S. 20I3. Overview of child mortality in South Africa. Research Unit, Parliament of the Republic of South Africa.

WHO 1978. Declaration of Alma-Ata: International Conference on Primary Health Care. Alma-Ata, USSR: World Health Organization.

\section{APPENDIX}

Table 9 Municipal level estimates of infant and U5M rates with level of poverty and inequality*

\begin{tabular}{|c|c|c|c|c|c|c|c|c|c|c|c|}
\hline \multirow[b]{2}{*}{ Province } & \multirow[b]{2}{*}{ Municipality } & \multirow[b]{2}{*}{ IMR } & \multirow[b]{2}{*}{ U5MR } & \multirow[b]{2}{*}{ PHCR } & \multirow[b]{2}{*}{ Gl } & \multirow[b]{2}{*}{$\begin{array}{c}\text { LS } \\
\text { PHCR }\end{array}$} & \multirow[b]{2}{*}{ SMR } & \multicolumn{4}{|c|}{ Ranks } \\
\hline & & & & & & & & U5M & PV & II & LSP \\
\hline WC & City of Cape Town & 18.3 & 24.0 & 29.6 & 0.673 & 16.9 & 1.00 & 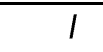 & 33 & 86 & 14 \\
\hline WC & Mossel Bay & 19.7 & 25.8 & 34.4 & 0.655 & 14.3 & 1.08 & 2 & 48 & 55 & 3 \\
\hline WC & Knysna & 20.4 & 26.6 & 34.9 & 0.704 & 27.2 & 1.11 & 3 & 52 & 170 & 60 \\
\hline WC & Overstrand & 20.6 & 27.0 & 32.0 & 0.648 & 20.9 & 1.13 & 4 & 40 & 47 & 25 \\
\hline WC & Bitou & 21.0 & 27.5 & 37.2 & 0.706 & 24.5 & 1.15 & 5 & 72 & 176 & 46 \\
\hline WC & Stellenbosch & 21.2 & 27.7 & 33.7 & 0.681 & 20.6 & 1.16 & 6 & 44 & 104 & 24 \\
\hline WC & George & 21.6 & 28.2 & 31.4 & 0.652 & 19.2 & 1.18 & 7 & 38 & 52 & 20 \\
\hline WC & Drakenstein & 21.7 & 28.4 & 28.4 & 0.667 & 15.1 & 1.18 & 8 & 23 & 75 & 7 \\
\hline WC & Breede Valley & 23.3 & 30.4 & 28.7 & 0.651 & 24.1 & 1.27 & 9 & 27 & 50 & 43 \\
\hline WC & Theewaterskloof & 23.3 & 30.5 & 27.9 & 0.647 & 21.7 & 1.27 & 10 & 21 & 42 & 28 \\
\hline LP & Thulamela & 22.2 & 30.6 & 60.1 & 0.688 & 77.3 & 1.28 & 11 & 195 & 123 & 184 \\
\hline WC & Saldanha Bay & 23.9 & 31.2 & 27.8 & 0.636 & 13.3 & 1.30 & 12 & 19 & 26 & I \\
\hline GT & City of Tshwane & 23.5 & 31.3 & 28.4 & 0.663 & 22.0 & 1.31 & 13 & 24 & 68 & 31 \\
\hline GT & City of Johannesburg & 24.0 & 32.2 & 29.7 & 0.694 & 17.2 & 1.34 & 14 & 34 & 146 & 15 \\
\hline EC & Nelson Mandela Bay & 24.2 & 32.3 & 40.7 & 0.694 & 15.9 & 1.35 & 15 & 104 & 144 & 11 \\
\hline WC & Cape Agulhas & 24.8 & 32.5 & 21.0 & 0.623 & 14.8 & 1.35 & 16 & 1 & 13 & 4 \\
\hline WC & Oudtshoorn & 23.9 & 32.5 & 36.1 & 0.688 & 23.5 & 1.36 & 17 & 66 & 122 & 38 \\
\hline WC & Swartland & 24.6 & 33.2 & 25.5 & 0.660 & 16.2 & 1.39 & 18 & 12 & 63 & 13 \\
\hline WC & Langeberg & 25.6 & 33.5 & 28.8 & 0.677 & 18.5 & 1.40 & 19 & 28 & 94 & 16 \\
\hline WC & Hessequa & 25.7 & 33.6 & 23.0 & 0.613 & 13.5 & 1.40 & 20 & 5 & 9 & 2 \\
\hline WC & Bergrivier & 26.0 & 34.0 & 21.6 & 0.592 & 19.2 & 1.42 & 21 & 2 & 4 & 19 \\
\hline WC & Swellendam & 27.1 & 35.4 & 24.2 & 0.627 & 22.1 & 1.47 & 22 & 9 & 16 & 32 \\
\hline LP & Mutale & 25.9 & 35.7 & 61.9 & 0.707 & 87.5 & 1.49 & 23 & 206 & 182 & 208 \\
\hline WC & Laingsburg & 27.4 & 35.8 & 23.0 & 0.636 & 30.7 & 1.49 & 24 & 4 & 28 & 81 \\
\hline LP & Polokwane & 26.2 & 36.0 & 40.4 & 0.711 & 49.7 & 1.50 & 25 & 103 & 191 & 129 \\
\hline NC & Richtersveld & 27.8 & 36.1 & 22.9 & 0.614 & 15.5 & 1.51 & 26 & 3 & 10 & 8 \\
\hline LP & Makhado & 26.3 & 36.3 & 55.3 & 0.697 & 76.2 & 1.51 & 27 & 173 & 152 & 178 \\
\hline WC & Beaufort West & 28.1 & 36.7 & 37.8 & 0.691 & 15.9 & 1.53 & 28 & 78 & 131 & 10 \\
\hline NC & Nama Khoi & 28.4 & 36.9 & 29.2 & 0.684 & 16.0 & 1.54 & 29 & 32 & 112 & 12 \\
\hline WC & Witzenberg & 28.7 & 37.5 & 23.4 & 0.639 & 25.7 & 1.56 & 30 & 7 & 32 & 50 \\
\hline $\mathrm{EC}$ & Buffalo City & 28.9 & 38.6 & 42.7 & 0.705 & 38.4 & 1.61 & 31 & 115 & 171 & 110 \\
\hline WC & Kannaland & 29.6 & 38.7 & 36.5 & 0.719 & 27.0 & 1.61 & 32 & 69 & 203 & 57 \\
\hline WC & Matzikama & 29.9 & 39.0 & 25.3 & 0.658 & 30.4 & 1.63 & 33 & 11 & 60 & 77 \\
\hline WC & Cederberg & 30.1 & 39.4 & 24.7 & 0.636 & 28.5 & 1.64 & 34 & 10 & 24 & 68 \\
\hline LP & Lepele-Nkumpi & 28.8 & 39.6 & 55.3 & 0.704 & 66.2 & 1.65 & 35 & 173 & 167 & 153 \\
\hline LP & Makhuduthamaga & 28.9 & 39.7 & 64.7 & 0.718 & 81.0 & 1.66 & 36 & 218 & 202 & 189 \\
\hline LP & Ba-Phalaborwa & 28.9 & 39.8 & 43.0 & 0.698 & 50.4 & 1.66 & 37 & 116 & 158 & 131 \\
\hline WC & Prince Albert & 31.0 & 40.4 & 35.8 & 0.691 & 26.2 & 1.69 & 38 & 63 & 132 & 52 \\
\hline 4391 & & & & & & & & $: / /$ & in & als.ac. & \\
\hline
\end{tabular}


Ranks

\begin{tabular}{llllllllllllllllll}
\cline { 5 - 7 } & Province & Municipality & IMR & U5MR & PHCR & GI & LS & SMR & U5M & PV & II & LS
\end{tabular}

\begin{tabular}{|c|c|c|c|c|c|c|c|c|c|c|c|}
\hline GT & Randfontein & 29.5 & 40.8 & 28.1 & 0.628 & 22.7 & 1.70 & 39 & 22 & 17 & 35 \\
\hline $\mathrm{NC}$ & Sol Plaatjie & 31.6 & 41.0 & 35.5 & 0.695 & 21.7 & 1.71 & 40 & 58 & 148 & 27 \\
\hline GT & Mogale City & 29.7 & 41.1 & 31.1 & 0.667 & 25.3 & 1.71 & 41 & 36 & 75 & 48 \\
\hline LP & Fetakgomo & 30.1 & 41.5 & 56.3 & 0.710 & 72.4 & 1.73 & 42 & 181 & 188 & 166 \\
\hline LP & Greater Tzaneen & 30.2 & 41.5 & 52.2 & 0.719 & 76.9 & 1.73 & 43 & 152 & 204 & 182 \\
\hline LP & Aganang & 30.3 & 41.6 & 56.2 & 0.639 & 75.1 & 1.74 & 44 & 180 & 33 & 172 \\
\hline LP & Greater Giyani & 30.8 & 42.3 & 65.3 & 0.704 & 82.2 & 1.77 & 45 & 219 & 168 & 191 \\
\hline LP & Molemole & 30.8 & 42.4 & 52.7 & 0.697 & 67.7 & 1.77 & 46 & 158 & 154 & 157 \\
\hline NC & Emthanjeni & 33.0 & 42.8 & 35.7 & 0.660 & 21.5 & 1.79 & 47 & 59 & 64 & 26 \\
\hline LP & Musina & 31.2 & 42.9 & 35.8 & 0.679 & 45.7 & 1.79 & 48 & 63 & 100 & 125 \\
\hline LP & Greater Tubatse & 31.2 & 43.0 & 53.2 & 0.708 & 76.0 & 1.79 & 49 & 160 & 184 & 175 \\
\hline LP & Bela-Bela & 31.5 & 43.4 & 33.7 & 0.666 & 29.5 & 1.81 & 50 & 45 & 73 & $7 I$ \\
\hline GT & Ekurhuleni & 31.6 & 43.7 & 33.6 & 0.664 & 23.5 & 1.82 & 51 & 43 & 70 & 40 \\
\hline EC & Kouga & 32.9 & 43.9 & 36.8 & 0.697 & 28.0 & 1.83 & 52 & 70 & 154 & 65 \\
\hline LP & Greater Letaba & 32.0 & 44.0 & 59.7 & 0.685 & 84.3 & 1.84 & 53 & 192 & 116 & 196 \\
\hline LP & Elias Motsoaledi & 32.2 & 44.3 & 56.5 & 0.691 & 70.4 & 1.85 & 54 & 183 & 129 & 163 \\
\hline NC & Mier & 34.3 & 44.5 & 36.8 & 0.693 & 36.0 & 1.86 & 55 & $7 I$ & 137 & 97 \\
\hline GT & Emfuleni & 32.3 & 44.6 & 40.0 & 0.679 & 15.0 & 1.86 & 56 & 98 & 102 & 6 \\
\hline LP & Maruleng & 32.6 & 44.8 & 61.3 & 0.731 & 84.2 & 1.87 & 57 & 204 & 223 & 195 \\
\hline $\mathrm{NC}$ & Renosterberg & 34.7 & 45.1 & 38.2 & 0.655 & 27.2 & 1.88 & 58 & 81 & 56 & 59 \\
\hline LP & Lephalale & 32.8 & 45.1 & 35.0 & 0.688 & 52.6 & 1.88 & 59 & 53 & 120 & 134 \\
\hline NW & Rustenburg & 33.3 & 45.5 & 28.9 & 0.597 & 40.1 & 1.90 & 60 & 31 & 6 & 114 \\
\hline NC & //Khara Hais & 35.1 & 45.6 & 35.0 & 0.685 & 25.2 & 1.90 & 61 & 54 & 114 & 47 \\
\hline NC & Kamiesberg & 35.5 & 46.1 & 39.5 & 0.703 & 30.0 & 1.92 & 62 & 91 & 165 & 73 \\
\hline LP & Mogalakwena & 33.5 & 46.1 & 53.9 & 0.698 & 60.0 & 1.92 & 63 & 165 & 155 & 146 \\
\hline LP & Ephraim Mogale & 33.6 & 46.2 & 55.2 & 0.705 & 78.1 & 1.93 & 64 & 170 & 173 & 187 \\
\hline NC & Khâi-Ma & 35.7 & 46.4 & 26.4 & 0.582 & 36.0 & 1.93 & 65 & 15 & 2 & 95 \\
\hline $\mathrm{GT}$ & Midvaal & 33.9 & 46.8 & 28.6 & 0.651 & 27.0 & 1.95 & 66 & 26 & 51 & 56 \\
\hline LP & Thabazimbi & 34.0 & 46.8 & 25.6 & 0.597 & 39.9 & 1.95 & 67 & 13 & 5 & $1 / 3$ \\
\hline NW & Moretele & 34.3 & 46.8 & 51.4 & 0.607 & 66.7 & 1.95 & 68 & 149 & 8 & 154 \\
\hline NC & Umsobomvu & 36.1 & 46.9 & 44.3 & 0.707 & 29.1 & 1.96 & 69 & 121 & 182 & 70 \\
\hline NC & Siyathemba & 36.5 & 47.4 & 35.8 & 0.672 & 28.1 & 1.98 & 70 & 61 & 85 & 66 \\
\hline NW & Local Mun. of Madibeng & 35.0 & 47.8 & 34.3 & 0.648 & 61.2 & 1.99 & 71 & 47 & 45 & 148 \\
\hline$M P$ & Bushbuckridge & 34.6 & 48.4 & 63.9 & 0.690 & 78.0 & 2.02 & 72 & 214 & 127 & 185 \\
\hline GT & Westonaria & 35.6 & 49.2 & 39.8 & 0.601 & 46.2 & 2.05 & 73 & 95 & 7 & 126 \\
\hline LP & Mookgopong & 35.8 & 49.2 & 32.2 & 0.630 & 35.3 & 2.05 & 74 & 41 & 19 & 91 \\
\hline EC & Kou-Kamma & 37.0 & 49.3 & 31.5 & 0.666 & 27.9 & 2.06 & 75 & 39 & 71 & 64 \\
\hline $\mathrm{NC}$ & Hantam & 38.3 & 49.6 & 28.5 & 0.720 & 26.9 & 2.07 & 76 & 25 & 206 & 55 \\
\hline MP & Emalahleni & 35.7 & 49.8 & 27.8 & 0.638 & 33.6 & 2.08 & 77 & 20 & 31 & 89 \\
\hline $\mathrm{EC}$ & Makana & 37.5 & 50.0 & 37.5 & 0.698 & 23.5 & 2.09 & 78 & 76 & 157 & 40 \\
\hline NC & Thembelihle & 38.7 & 50.2 & 38.6 & 0.733 & 39.1 & 2.09 & 79 & 84 & 224 & 112 \\
\hline NW & Moses Kotane & 37.0 & 50.4 & 43.9 & 0.632 & 55.5 & 2.10 & 80 & 118 & 21 & 142 \\
\hline$K Z$ & eThekwini & 37.1 & 50.8 & 37.4 & 0.681 & 30.4 & 2.12 & 81 & 74 & 105 & 76 \\
\hline $\mathrm{NC}$ & Karoo Hoogland & 39.2 & 50.8 & 27.3 & 0.723 & 48.0 & 2.12 & 82 & 18 & 213 & 127 \\
\hline EC & Lukanji & 38.1 & 50.8 & 47.2 & 0.696 & 36.0 & 2.12 & 83 & 129 & 150 & 94 \\
\hline NC & Ubuntu & 39.3 & 50.9 & 38.4 & 0.760 & 35.6 & 2.12 & 84 & 83 & 232 & 92 \\
\hline NC & Kareeberg & 39.3 & 50.9 & 37.2 & 0.678 & 37.3 & 2.13 & 85 & 73 & 98 & 103 \\
\hline NC & Kgatelopele & 39.4 & 51.1 & 26.1 & 0.685 & 15.6 & 2.13 & 86 & 14 & 115 & 9 \\
\hline GT & Merafong City & 37.3 & 51.5 & 31.3 & 0.583 & 31.8 & 2.15 & 87 & 37 & 3 & 85 \\
\hline EC & Baviaans & 38.7 & 51.7 & 35.8 & 0.679 & 20.4 & 2.16 & 88 & 64 & 101 & 23 \\
\hline GT & Lesedi & 37.5 & 51.7 & 34.9 & 0.671 & 20.2 & 2.16 & 89 & 51 & 81 & 22 \\
\hline
\end{tabular}




\begin{tabular}{|c|c|c|c|c|c|c|c|c|c|c|c|}
\hline \multirow[b]{2}{*}{ Province } & \multirow[b]{2}{*}{ Municipality } & \multirow[b]{2}{*}{ IMR } & \multirow[b]{2}{*}{ U5MR } & \multirow[b]{2}{*}{ PHCR } & \multirow[b]{2}{*}{ Gl } & \multirow[b]{2}{*}{$\begin{array}{c}\text { LS } \\
\text { PHCR }\end{array}$} & \multirow[b]{2}{*}{ SMR } & \multicolumn{4}{|c|}{ Ranks } \\
\hline & & & & & & & & U5M & PV & II & LSP \\
\hline EC & Mnquma & 39.2 & 52.2 & 53.8 & 0.642 & 84.7 & 2.18 & 90 & 164 & 35 & 198 \\
\hline LP & Modimolle & 38.1 & 52.3 & 36.2 & 0.661 & 31.5 & 2.18 & 91 & 67 & 66 & 84 \\
\hline MP & Mbombela & 37.6 & 52.5 & 40.3 & 0.711 & 48.9 & 2.19 & 92 & 101 & 192 & 128 \\
\hline NW & Tlokwe City Council & 38.6 & 52.6 & 35.7 & 0.672 & 22.3 & 2.19 & 93 & 60 & 83 & 33 \\
\hline EC & Camdeboo & 39.5 & 52.7 & 39.4 & 0.699 & 19.5 & 2.20 & 94 & 90 & 159 & 21 \\
\hline NC & Ga-Segonyana & 40.9 & 53.0 & 47.3 & 0.706 & 62.1 & 2.21 & 95 & 130 & 178 & 150 \\
\hline MP & Steve Tshwete & 38.3 & 53.5 & 26.7 & 0.629 & 22.0 & 2.23 & 96 & 17 & 18 & 29 \\
\hline MP & Dr JS Moroka & 38.4 & 53.6 & 54.2 & 0.637 & 61.0 & 2.24 & 97 & 167 & 29 & 147 \\
\hline EC & Great Kei & 40.2 & 53.6 & 51.2 & 0.743 & 70.8 & 2.24 & 98 & 146 & 228 & 164 \\
\hline EC & Ngqushwa & 40.2 & 53.6 & 53.2 & 0.576 & 86.0 & 2.24 & 99 & 159 & 1 & 202 \\
\hline MP & Thaba Chweu & 38.5 & 53.8 & 28.9 & 0.636 & 43.6 & 2.25 & 100 & 30 & 26 & 120 \\
\hline LP & Blouberg & 39.3 & 54.0 & 62.1 & 0.711 & 82.0 & 2.25 & 101 & 207 & 189 & 190 \\
\hline NC & Kai !Garib & 41.7 & 54.0 & 26.4 & 0.641 & 43.6 & 2.25 & 102 & 16 & 34 & 119 \\
\hline FS & Metsimaholo & 38.1 & 54.1 & 35.9 & 0.693 & 23.7 & 2.26 & 103 & 65 & 136 & 41 \\
\hline NC & Tsantsabane & 42.1 & 54.6 & 33.3 & 0.717 & 36.0 & 2.28 & 104 & 42 & 201 & 96 \\
\hline EC & King Sabata Dalindyebo & 41.2 & 54.9 & 56.1 & 0.729 & 72.0 & 2.29 & 105 & 179 & 220 & 165 \\
\hline KZ & The Msunduzi & 40.1 & 55.0 & 39.7 & 0.702 & 38.1 & 2.29 & 106 & 94 & 163 & 109 \\
\hline EC & Nkonkobe & 41.4 & 55.1 & 52.5 & 0.661 & 68.7 & 2.30 & 107 & 156 & 67 & 160 \\
\hline NC & Siyancuma & 43.2 & 56.0 & 41.1 & 0.710 & 37.4 & 2.34 & 108 & 105 & 187 & 106 \\
\hline NC & !Kheis & 43.4 & 56.3 & 42.3 & 0.702 & 53.5 & 2.35 & 109 & 113 & 164 & 137 \\
\hline NC & Gamagara & 43.5 & 56.3 & 23.3 & 0.652 & 26.5 & 2.35 & 110 & 6 & 53 & 53 \\
\hline MP & Thembisile & 40.6 & 56.6 & 51.3 & 0.644 & 53.9 & 2.36 & 111 & 148 & 39 & 138 \\
\hline NC & Dikgatlong & 44.1 & 57.2 & 49.8 & 0.644 & 37.2 & 2.39 & 112 & 139 & 38 & 102 \\
\hline EC & Amahlathi & 43.2 & 57.5 & 52.5 & 0.675 & 76.3 & 2.40 & 113 & 155 & 91 & 180 \\
\hline EC & Nxuba & 43.4 & 57.8 & 48.5 & 0.670 & 37.4 & 2.41 & 114 & 135 & 79 & 104 \\
\hline FS & Mangaung & 40.8 & 57.8 & 34.8 & 0.694 & 26.8 & 2.41 & 115 & 50 & 143 & 54 \\
\hline NW & Mafikeng & 42.6 & 58.1 & 43.6 & 0.712 & 51.2 & 2.42 & 116 & 117 & 193 & 132 \\
\hline NC & Phokwane & 44.8 & 58.1 & 45.7 & 0.721 & 37.1 & 2.42 & 117 & 124 & 208 & 101 \\
\hline EC & Blue Crane Route & 43.7 & 58.3 & 43.9 & 0.734 & 25.6 & 2.43 & 118 & 119 & 225 & 49 \\
\hline NC & Magareng & 45.3 & 58.7 & 49.6 & 0.663 & 23.7 & 2.45 & 119 & 138 & 69 & 42 \\
\hline EC & Sundays River Valley & 44.3 & 59.0 & 40.3 & 0.620 & 45.2 & 2.46 & 120 & 102 & 12 & 123 \\
\hline EC & Sakhisizwe & 44.4 & 59.2 & 55.0 & 0.725 & 74.5 & 2.47 & 121 & 169 & 217 & 171 \\
\hline EC & Ikwezi & 44.5 & 59.3 & 51.2 & 0.657 & 25.9 & 2.47 & 122 & 146 & 58 & 51 \\
\hline EC & Inxuba Yethemba & 44.5 & 59.3 & 38.1 & 0.695 & 15.0 & 2.47 & 123 & 80 & 148 & 5 \\
\hline EC & Maletswai & 45.4 & 60.5 & 39.7 & 0.693 & 29.7 & 2.52 & 124 & 94 & 140 & 72 \\
\hline MP & Govan Mbeki & 43.6 & 60.8 & 35.1 & 0.689 & 23.0 & 2.54 & 125 & 56 & 125 & 37 \\
\hline EC & Intsika Yethu & 45.8 & 61.0 & 57.4 & 0.678 & 93.9 & 2.54 & 126 & 187 & 97 & 224 \\
\hline EC & Mbhashe & 46.2 & 61.5 & 62.5 & 0.683 & 94.9 & 2.57 & 127 & 208 & 109 & 230 \\
\hline $\mathrm{KZ}$ & uMngeni & 45.0 & 61.5 & 28.8 & 0.690 & 28.3 & 2.57 & 128 & 29 & 127 & 67 \\
\hline MP & Umjindi & 44.4 & 61.9 & 30.7 & 0.644 & 38.8 & 2.58 & 129 & 35 & 38 & 111 \\
\hline MP & Victor Khanye & 44.4 & 61.9 & 39.6 & 0.678 & 30.9 & 2.58 & 130 & 92 & 95 & 82 \\
\hline $\mathrm{KZ}$ & Umdoni & 45.3 & 61.9 & 38.7 & 0.693 & 54.3 & 2.58 & 131 & 85 & 138 & 139 \\
\hline EC & Ndlambe & 46.7 & 62.2 & 41.7 & 0.708 & 33.9 & 2.60 & 132 & 108 & 183 & 90 \\
\hline KZ & Mandeni & 45.7 & 62.5 & 46.1 & 0.643 & 69.8 & 2.61 & 133 & 125 & 36 & 161 \\
\hline FS & Moqhaka & 44.9 & 63.6 & 37.7 & 0.675 & 18.6 & 2.65 & 134 & 77 & 90 & 17 \\
\hline KZ & KwaDukuza & 46.5 & 63.6 & 33.9 & 0.683 & 54.6 & 2.65 & 135 & 46 & 109 & 140 \\
\hline KZ & uMhlathuze & 46.6 & 63.7 & 37.9 & 0.684 & 36.6 & 2.66 & 136 & 79 & 112 & 99 \\
\hline NW & Ramotshere Moiloa & 47.1 & 64.1 & 50.5 & 0.681 & 67.0 & 2.68 & 137 & 142 & 103 & 155 \\
\hline EC & Umzimvubu & 48.3 & 64.2 & 61.1 & 0.703 & 91.6 & 2.68 & 138 & 200 & 166 & 217 \\
\hline EC & Tsolwana & 48.4 & 64.5 & 51.8 & 0.649 & 68.7 & 2.69 & 139 & 151 & 48 & 159 \\
\hline 4393 & & & & & & & & ttp://ap & s.journ & . & \\
\hline
\end{tabular}


Ranks

\begin{tabular}{lllllllllllllllll}
\cline { 5 - 7 } Province & Municipality & IMR & U5MR & PHCR & GI & LS & SMR & U5M & PV & II & LS
\end{tabular}

\begin{tabular}{|c|c|c|c|c|c|c|c|c|c|c|c|}
\hline$M P$ & Emakhazeni & 46.4 & 64.6 & 35.0 & 0.645 & 33.1 & 2.70 & 140 & 55 & 40 & 88 \\
\hline KZ & Greater Kokstad & 47.3 & 64.7 & 38.7 & 0.693 & 37.4 & 2.70 & 141 & 86 & 135 & 105 \\
\hline $\mathrm{KZ}$ & Hibiscus Coast & 47.5 & 65.0 & 38.2 & 0.693 & 55.7 & $2.7 I$ & 142 & 82 & 140 & 143 \\
\hline NW & City of Matlosana & 47.9 & 65.2 & 41.2 & 0.678 & 18.8 & 2.72 & 143 & 106 & 99 & 18 \\
\hline EC & Nyandeni & 49.6 & 66.0 & 69.3 & 0.674 & 94.8 & 2.75 & 144 & 229 & 88 & 229 \\
\hline NC & Joe Morolong & 51.0 & 66.1 & 61.6 & 0.748 & 86.8 & 2.76 & 145 & 205 & 229 & 204 \\
\hline $\mathrm{EC}$ & Mhlontlo & 50.1 & 66.6 & 63.1 & 0.655 & 93.7 & 2.78 & 146 & 210 & 55 & 222 \\
\hline EC & Emalahleni & 50.7 & 67.4 & 57.3 & 0.650 & 85.6 & 2.81 & 147 & 185 & 49 & 201 \\
\hline FS & Matjhabeng & 47.9 & 67.8 & 42.0 & 0.667 & 22.0 & 2.83 & 148 & 109 & 77 & 30 \\
\hline KZ & Umhlabuyalingana & 49.8 & 68.1 & 67.9 & 0.721 & 91.6 & 2.84 & 149 & 225 & 210 & 216 \\
\hline MP & Nkomazi & 49.0 & 68.3 & 55.9 & 0.696 & 67.4 & 2.85 & 150 & 175 & 149 & 156 \\
\hline EC & Senqu & 52.6 & 70.0 & 56.1 & 0.660 & 76.1 & 2.92 & 151 & 178 & 63 & 177 \\
\hline FS & Mafube & 50.1 & 71.0 & 47.7 & 0.688 & 27.9 & 2.96 & 152 & 133 & 124 & 63 \\
\hline FS & Ngwathe & 50.4 & 71.4 & 45.2 & 0.683 & 22.8 & 2.98 & 153 & 123 & 107 & 36 \\
\hline FS & Kopanong & 50.8 & 71.9 & 38.9 & 0.716 & 24.4 & 3.00 & 154 & 88 & 198 & 45 \\
\hline FS & Mantsopa & 50.8 & 72.0 & 42.2 & 0.714 & 32.4 & 3.00 & 155 & 111 & 197 & 87 \\
\hline EC & Gariep & 54.2 & 72.1 & 38.9 & 0.694 & 30.4 & 3.01 & 156 & 87 & 142 & 78 \\
\hline FS & Naledi & 51.0 & 72.2 & 48.8 & 0.710 & 30.9 & 3.01 & 157 & 136 & 185 & 83 \\
\hline MP & Dipaleseng & 51.9 & 72.3 & 39.9 & 0.635 & 32.0 & 3.02 & 158 & 96 & 23 & 86 \\
\hline$K Z$ & Ubuhlebezwe & 55.1 & 72.8 & 59.7 & 0.684 & 86.7 & 3.04 & 159 & 193 & 113 & 203 \\
\hline EC & Inkwanca & 53.3 & 73.3 & 46.9 & 0.670 & 24.4 & 3.06 & 160 & 128 & 80 & 44 \\
\hline$K Z$ & Ndwedwe & 53.7 & 73.4 & 60.3 & 0.625 & 91.0 & 3.06 & 161 & 196 & 14 & 215 \\
\hline EC & Elundini & 55.3 & 73.5 & 59.2 & 0.710 & 88.8 & 3.07 & 162 & 190 & 187 & 211 \\
\hline $\mathrm{KZ}$ & Endumeni & 54.1 & 74.0 & 39.0 & 0.661 & 27.3 & 3.09 & 163 & 89 & 65 & 61 \\
\hline FS & Masilonyana & 52.6 & 74.4 & 47.5 & 0.659 & 30.2 & 3.10 & 164 & 132 & 61 & 74 \\
\hline EC & Engcobo & 56.0 & 74.5 & 63.4 & 0.713 & 94.2 & 3.11 & 165 & 211 & 195 & 227 \\
\hline FS & Dihlabeng & 52.7 & 74.5 & 34.5 & 0.700 & 27.1 & 3.11 & 166 & 49 & 162 & 58 \\
\hline NW & Kgetlengrivier & 54.9 & 74.7 & 42.2 & 0.705 & 45.6 & 3.11 & 167 & 112 & 173 & 124 \\
\hline$K Z$ & Umzumbe & 54.8 & 74.9 & 64.5 & 0.636 & 92.6 & 3.12 & 168 & 217 & 27 & 220 \\
\hline$K Z$ & uMlalazi & 54.9 & 74.9 & 54.7 & 0.696 & 79.3 & 3.13 & 169 & 168 & 151 & 188 \\
\hline EC & Ngquza Hill & 56.6 & 75.3 & 69.5 & 0.734 & 94.5 & 3.14 & 170 & 230 & 226 & 228 \\
\hline NW & Ditsobotla & 55.5 & 75.4 & 47.4 & 0.722 & 54.9 & 3.15 & 171 & 131 & 211 & 141 \\
\hline $\mathrm{KZ}$ & Mtubatuba & 55.2 & 75.5 & 56.1 & 0.726 & 73.1 & 3.15 & 172 & 177 & 218 & 168 \\
\hline$K Z$ & Impendle & 55.5 & 75.8 & 59.3 & 0.647 & 87.0 & 3.16 & 173 & 191 & 41 & 206 \\
\hline NW & Ventersdorp & 55.8 & 75.9 & 52.5 & 0.694 & 58.4 & 3.16 & 174 & 155 & 146 & 145 \\
\hline KZ & Richmond & 55.8 & 76.2 & 46.7 & 0.690 & 78.1 & 3.18 & 175 & 127 & 128 & 187 \\
\hline EC & Matatiele & 57.5 & 76.4 & 58.8 & 0.672 & 87.0 & 3.19 & 176 & 188 & 83 & 205 \\
\hline$K Z$ & Ingwe & 56.0 & 76.5 & 61.2 & 0.727 & 93.3 & 3.19 & 177 & 202 & 219 & 221 \\
\hline MP & Albert Luthuli & 55.1 & 76.6 & 55.4 & 0.720 & 65.9 & 3.20 & 178 & 174 & 207 & 152 \\
\hline $\mathrm{KZ}$ & Umzimkhulu & 56.1 & 76.7 & 64.4 & 0.673 & 91.6 & 3.20 & 179 & 216 & 87 & 218 \\
\hline FS & Mohokare & 54.8 & 77.5 & 46.5 & 0.720 & 37.6 & 3.23 & 180 & 126 & 205 & 107 \\
\hline$K Z$ & Mkhambathini & 56.8 & 77.6 & 44.2 & 0.632 & 85.0 & 3.24 & 181 & 120 & 20 & 200 \\
\hline FS & Letsemeng & 55.0 & 77.7 & 40.2 & 0.667 & 30.7 & 3.24 & 182 & 100 & 76 & 80 \\
\hline MP & Msukaligwa & 56.1 & 78.1 & 36.3 & 0.686 & 37.7 & 3.26 & 183 & 68 & 118 & 108 \\
\hline EC & Ntabankulu & 58.9 & 78.3 & 69.8 & 0.674 & 95.4 & 3.26 & 184 & 231 & 89 & 233 \\
\hline FS & Maluti a Phofung & 55.4 & 78.4 & 56.1 & 0.683 & 53.5 & 3.27 & 185 & 177 & 106 & 137 \\
\hline$K Z$ & Kwa Sani & 57.6 & 78.7 & 23.5 & 0.657 & 52.0 & 3.28 & 186 & 8 & 59 & 133 \\
\hline$K Z$ & Ezingoleni & 57.6 & 78.7 & 60.0 & 0.648 & 90.8 & 3.28 & 187 & 194 & 44 & 214 \\
\hline$K Z$ & Mfolozi & 57.7 & 78.8 & 57.4 & 0.648 & 75.5 & 3.29 & 188 & 186 & 46 & 174 \\
\hline FS & Setsoto & 56.1 & 79.4 & 50.2 & 0.704 & 40.5 & 3.31 & 189 & 140 & 169 & 115 \\
\hline MP & Lekwa & 57.2 & 79.6 & 35.4 & 0.677 & 22.5 & 3.32 & 190 & 57 & 94 & 34 \\
\hline
\end{tabular}




\begin{tabular}{|c|c|c|c|c|c|c|c|c|c|c|c|}
\hline \multirow[b]{2}{*}{ Province } & \multirow[b]{2}{*}{ Municipality } & \multirow[b]{2}{*}{ IMR } & \multirow[b]{2}{*}{ U5MR } & \multirow[b]{2}{*}{ PHCR } & \multirow[b]{2}{*}{ Gl } & \multirow[b]{2}{*}{$\begin{array}{c}\text { LS } \\
\text { PHCR }\end{array}$} & \multirow[b]{2}{*}{ SMR } & \multicolumn{4}{|c|}{ Ranks } \\
\hline & & & & & & & & U5M & PV & II & LSP \\
\hline FS & Nala & 56.7 & 80.2 & 51.3 & 0.684 & 30.2 & 3.35 & 191 & 147 & 110 & 75 \\
\hline $\mathrm{EC}$ & Port St Johns & 60.5 & 80.3 & 72.0 & 0.730 & 96.5 & 3.35 & 192 & 233 & 222 & 234 \\
\hline NW & Naledi & 59.2 & 80.4 & 39.9 & 0.693 & 37.0 & 3.35 & 193 & 97 & 140 & 100 \\
\hline NW & Greater Taung & 59.2 & 80.4 & 60.9 & 0.687 & 82.5 & 3.36 & 194 & 199 & 119 & 192 \\
\hline NW & Lekwa-Teemane & 59.6 & 81.0 & 40.2 & 0.706 & 28.6 & 3.38 & 195 & 99 & 180 & 69 \\
\hline KZ & Vulamehlo & 59.7 & 81.5 & 63.1 & 0.620 & 94.0 & 3.40 & 196 & 209 & 11 & 225 \\
\hline$K Z$ & Emnambithi/Ladysmith & 59.7 & 81.5 & 48.4 & 0.700 & 43.8 & 3.40 & 197 & 134 & 161 & 121 \\
\hline KZ & Mpofana & 59.8 & 81.6 & 37.4 & 0.668 & 45.2 & 3.40 & 198 & 75 & 78 & 122 \\
\hline KZ & Newcastle & 60.0 & 81.9 & 51.7 & 0.724 & 30.5 & 3.42 & 199 & 150 & 215 & 79 \\
\hline$K Z$ & uMuziwabantu & 60.1 & 82.0 & 61.2 & 0.678 & 87.3 & 3.42 & 200 & 203 & 97 & 207 \\
\hline KZ & Maphumulo & 60.1 & 82.0 & 66.2 & 0.688 & 94.2 & 3.42 & 201 & 221 & 121 & 226 \\
\hline EC & Mbizana & 61.9 & 82.2 & 71.5 & 0.711 & 95.3 & 3.43 & 202 & 232 & 190 & 232 \\
\hline KZ & Hlabisa & 60.3 & 82.3 & 63.8 & 0.724 & 87.9 & 3.43 & 203 & 213 & 214 & 210 \\
\hline KZ & uMshwathi & 60.4 & 82.4 & 42.1 & 0.647 & 75.3 & 3.44 & 204 & 110 & 43 & 173 \\
\hline FS & Tswelopele & 58.7 & 83.0 & 50.2 & 0.692 & 27.9 & 3.46 & 205 & 141 & 134 & 62 \\
\hline KZ & Ulundi & 61.5 & 83.9 & 60.9 & 0.716 & 70.0 & 3.50 & 206 & 198 & 199 & 162 \\
\hline KZ & Jozini & 61.8 & 84.3 & 66.5 & 0.784 & 84.0 & 3.52 & 207 & 222 & 234 & 194 \\
\hline FS & Nketoana & 60.2 & 85.1 & 41.3 & 0.722 & 36.2 & 3.55 & 208 & 107 & 212 & 98 \\
\hline KZ & Dannhauser & 63.0 & 85.9 & 64.2 & 0.625 & 77.0 & 3.58 & 209 & 215 & 15 & 183 \\
\hline KZ & Imbabazane & 63.8 & 87.0 & 68.1 & 0.638 & 93.8 & 3.63 & 210 & 226 & 30 & 223 \\
\hline$K Z$ & Nkandla & 64.1 & 87.4 & 63.7 & 0.705 & 90.0 & 3.65 & 211 & 212 & 174 & 213 \\
\hline KZ & Umvoti & 64.5 & 87.9 & 49.3 & 0.672 & 76.0 & 3.67 & 212 & 137 & 83 & 176 \\
\hline KZ & Umtshezi & 64.6 & 88.1 & 52.4 & 0.751 & 49.8 & 3.68 & 213 & 153 & 230 & 130 \\
\hline KZ & Ntambanana & 64.6 & 88.1 & 67.0 & 0.692 & 92.5 & 3.68 & 214 & 224 & 133 & 219 \\
\hline KZ & The Big 5 False Bay & 65.1 & 88.7 & 56.5 & 0.775 & 72.5 & 3.70 & 215 & 184 & 233 & 167 \\
\hline FS & Phumelela & 63.6 & 89.8 & 44.9 & 0.666 & 42.4 & 3.75 & 216 & 122 & 72 & 118 \\
\hline NW & Tswaing & 67.5 & 91.6 & 56.3 & 0.706 & 65.1 & 3.82 & 217 & 182 & 178 & 151 \\
\hline NW & Kagisano/Molopo & 68.8 & 91.6 & 59.2 & 0.739 & 82.9 & 3.82 & 218 & 189 & 227 & 193 \\
\hline NW & Mamusa & 68.3 & 92.6 & 53.7 & 0.716 & 41.6 & 3.86 & 219 & 162 & 200 & 117 \\
\hline FS & Tokologo & 64.9 & 93.3 & 42.6 & 0.713 & 56.9 & 3.89 & 220 & 114 & 196 & 144 \\
\hline KZ & Indaka & 69.6 & 94.8 & 72.1 & 0.635 & 76.3 & 3.96 & 221 & 234 & 22 & 179 \\
\hline KZ & Nongoma & 69.9 & 95.2 & 66.7 & 0.706 & 87.6 & 3.97 & 222 & 223 & 179 & 209 \\
\hline$K Z$ & Mthonjaneni & 70.0 & 95.3 & 51.0 & 0.676 & 76.6 & 3.98 & 223 & 143 & 92 & 181 \\
\hline NW & Maquassi Hills & 72.7 & 98.4 & 53.7 & 0.725 & 35.8 & 4.11 & 224 & 161 & 216 & 93 \\
\hline NW & Ratlou & 73.1 & 99.1 & 61.2 & 0.698 & 89.1 & 4.13 & 225 & 201 & 156 & 212 \\
\hline MP & Pixley Ka Seme & 72.0 & 99.9 & 52.6 & 0.751 & 40.8 & 4.17 & 226 & 157 & 231 & 116 \\
\hline MP & Mkhondo & 72.5 & 100.5 & 53.9 & 0.721 & 61.4 & 4.19 & 227 & 166 & 210 & 149 \\
\hline KZ & Nqutu & 73.9 & 100.6 & 68.4 & 0.656 & 84.4 & 4.20 & 228 & 227 & 57 & 197 \\
\hline$K Z$ & Okhahlamba & 75.0 & 102.1 & 66.0 & 0.712 & 85.0 & 4.26 & 229 & 220 & 194 & 199 \\
\hline KZ & Abaqulusi & 75.9 & 103.3 & 53.7 & 0.729 & 52.8 & 4.31 & 230 & 163 & 221 & 135 \\
\hline KZ & Emadlangeni & 76.1 & 103.5 & 51.1 & 0.691 & 67.8 & 4.32 & 231 & 144 & 130 & 158 \\
\hline KZ & eDumbe & 77.8 & 105.8 & 60.6 & 0.686 & 73.6 & 4.41 & 232 & 197 & 117 & 169 \\
\hline$K Z$ & Msinga & 79.4 & 107.9 & 68.7 & 0.699 & 95.1 & 4.50 & 233 & 228 & 160 & 231 \\
\hline KZ & uPhongolo & 80.2 & 109.1 & 55.3 & 0.705 & 74.2 & 4.55 & 234 & 171 & 175 & 170 \\
\hline
\end{tabular}

* Notations - IMR: Infant mortality rate per thousand; U5MR: U5M rate per thousand; PHCR: \% income poverty headcount ratio; GI: Gini index; LSPHCR: living standard poverty head-count ratio; SMR: standardized mortality rate; U5M: U5M; IP: income poverty; II: income inequality; LSP: living standard poverty. 